\begin{tabular}{|c|l|}
\hline Title & $\begin{array}{l}\text { Solvent effects on the excited-state double proton transfer mechanism in the 7-azaindole dimer : a TDDFT study with } \\
\text { the polarizable continuum model }\end{array}$ \\
\hline Author(s) & Yu, Xue fang; Y amazaki, Shohei; Taketsugu, Tetsuya \\
\hline Citation & $\begin{array}{l}\text { Physical chemistry chemical physics, 19(34), 23289-23301 } \\
\text { https://doi.org/10.1039/c7cp04942k }\end{array}$ \\
\hline Issue Date & 2017-09-14 \\
\hline Doc URL & http://hdl.handle.net/2115/71462 \\
\hline Type & article (author version) \\
\hline File Information & PCCP19-34 23289-23301.pdf \\
\hline
\end{tabular}

Instructions for use 


\title{
Solvent Effect on the Excited-State Double Proton Transfer Mechanism in 7- Azaindole Dimer: A TDDFT Study with Polarizable Continuum Model
}

\author{
Xue-fang $\mathbf{Y u}^{\mathrm{a} *}$, Shohei Yamazaki ${ }^{\mathrm{b}}$, and Tetsuya Taketsugu ${ }^{\mathrm{c}}$ \\ a The Laboratory of Theoretical and Computational Chemistry, School of Chemistry and Chemical \\ Engineering, Yantai University, Yantai 264005, China \\ $b$ Department of Frontier Materials Chemistry, Graduate School of Science and Technology, Hirosaki \\ University, Hirosaki 036-8561 Japan \\ c Department of Chemistry, Faculty of Science, Hokkaido University, Sapporo 060-0810 Japan
}

\begin{abstract}
Solvent effects on the excited-state double proton transfer (ESDPT) mechanism in 7-azaindole (7AI) dimer were investigated using the time-dependent density functional theory (TDDFT) method. Excited-state potential energy profiles along the reaction paths in locally excited (LE) state and charge transfer (CT) state were calculated using polarizable continuum model (PCM) to include the solvent effect. A series of non-polar and polar solvents with different dielectric constant were used to examine the polarity effect on the ESDPT mechanism. The present results suggest that in non-polar solvent and polar solvent with a small dielectric constant, ESDPT follows the concerted mechanism, similar to the case in the gas phase. In polar solvent with a relatively large dielectric constant, however, ESDPT is likely to follow the stepwise mechanism via a stable zwitterionic intermediate in the LE state on the adiabatic potential energy surface, although inclusion of zero-point vibrational energy (ZPE) corrections again suggests the concerted mechanism. In the meantime, the stepwise reaction path involving the CT state with neutral intermediates is also examined, and is found to be less competitive than the concerted or stepwise path in the LE state in both non-polar and polar solvents. The present study provides a new insight into the experimental controversy of the ESDPT mechanism of 7AI dimer in a solution.
\end{abstract}




\section{Introduction}

In DNA base pairs, photo-induced proton transfer plays important roles in photo-stability, as well as in photo-induced DNA mutation. On one hand, proton transfer is correlated with the efficient nonradiative decay path in DNA base pairs [1-5]. After UV radiation, single proton transfer (SPT) occurs and an internal conversion is invoked from the first excited $\left(\mathrm{S}_{1}\right)$ to the ground $\left(\mathrm{S}_{0}\right)$ state. This decay process has been studied with dynamics simulations and static electronic structure calculations for DNA base pairs and their model systems [6-12]. Double proton transfer (DPT), on the other hand, can induce a tautomerization, leading to the mismatch in the duplication of the DNA $[13,14]$.

7-azaindole (7AI) dimer is one of the most studied models as DNA base pair, see Figure 1 for the molecular structure. The mechanism of the excited-state double proton transfer (ESDPT) in 7AI dimer is a very complicated and intriguing topic not only for chemists but also for biologists [15-56]. So far, two possible mechanisms have been proposed for ESDPT: concerted mechanism and stepwise mechanism. A notable way to distinguish these mechanisms is an examination of the existence of a single-proton-transferred intermediate. In the stepwise mechanism, the first proton transfer occurs with forming a stable intermediate, followed by the second proton transfer. The intermediate could be zwitterionic when formed in a locally excited (LE) state, while it could be neutral when formed in a charge transfer (CT) state. In the concerted mechanism, two protons are transferred simultaneously, without forming any intermediate. The concerted ESDPT in 7AI dimer can proceed synchronously or asynchronously (here, "synchronous" means the $\mathrm{C}_{2 \mathrm{~h}}$-conserved proton transfer while "asynchronous" means the $\mathrm{C}_{2 \mathrm{~h}}$ broken proton transfer). In both synchronous and asynchronous mechanisms, motions of the two protons are correlated and cooperative [45].

The mechanism of ESDPT in 7AI dimer has been in controversy for a long time. For details, see ref. [47] and the references therein. Until recently, several theoretical groups reach the consensus that ESDPT in the gas phase occurs with the concerted mechanism, by using high level quantum chemical calculations for the excited state [57-59]. Barbatti and co-workers further support the concerted mechanism through static quantum chemical calculations and dynamics simulations in the excited state [60]. 
For 7AI dimer in the condensed phase, however, the ESDPT mechanism seems to be obscure in both non-polar and polar solvent. In particular, due to a strong electrostatic interaction between solute and solvent, the reaction path and even the reaction mechanism can change from the gas-phase one. Zewail and co-workers reported the behavior of the excited 7AI-dimer in nonpolar solvent (n-heptane) and polar solvents (diethyl ether, dichloromethane and acetonitrile) using steady-state absorption and fluorescence spectroscopy, and time-resolved fluorescence upconversion $[29,32,46]$. They proposed the stepwise mechanism for ESDPT of 7AI-dimer, with the first and second proton transfers occurring on a different time scale (e.g., 0.13 and $1.2 \mathrm{ps}$ in non-polar solvents). Meanwhile, they revealed that the rate of the proton transfer is strongly dependent on the polarity and the isotopic composition, which was ascribed to the existence of a zwitterionic intermediate [56]. On the other hand, Takeuchi and Tahara [28,31,35,45] investigated dynamics of ESDPT of 7AI dimer in non-polar solvent hexane using a steady-state and femtosecond time-resolved fluorescence spectroscopy. They found that the intensity of time resolved fluorescence signal of 7AI dimer in hexane is significantly dependent on the excitation wavelength. The signal shows a biexponential decay (with time constants of 0.2 and $1.1 \mathrm{ps}$ ) and single exponential decay (with time constant of $1.1 \mathrm{ps)}$ ) after excitation with the short wavelength $(280 \mathrm{~nm})$ and the long wavelength $(313 \mathrm{~nm})$, respectively. For the biexponential decay, the faster component was assigned to the internal conversion from the ${ }^{1} \mathrm{~L}_{b}$ to ${ }^{1} \mathrm{~L}_{a}$ state, while the slower component was assigned to the concerted ESDPT in the $\mathrm{S}_{1}$ state, because the faster component was not observed when the red-edge of the $\mathrm{S}_{1}-\mathrm{S}_{0}$ absorption $(313 \mathrm{~nm})$ was excited. Moreover, the tautomer fluorescence rises in accordance with a disappearance of the dimer fluorescence within the single exponential behavior, which excludes the formation of the intermediate that should appear in the stepwise mechanism.

Thus, extensive experimental studies have been performed on ESDPT in several nonpolar and polar solvents. However, theoretical studies about the effect of solvent polarity on the ESDPT mechanism are still scant.

In a previous report [57], we revealed that ESDPT of 7AI dimer in the gas phase is likely to follow the concerted but asynchronous mechanism in the LE state, at the lowest excitation energy. We noticed that the dipole moment of 7AI dimer exhibits non-zero values along the asynchronous-concerted reaction path, and thus, the reaction path might be affected by the 
polarity of the solvent. Existence of the intermediate along the reaction path is one important feature in the stepwise mechanism. Locating the intermediate and determining the electronic character is of great significance for clarifying the proton transfer mechanism in a solution.

In this study, we explore excited-state potential energy surfaces of ESDPT in 7AI dimer with a series of non-polar and polar solvents through quantum chemical calculations to understand the relation of solvent polarity and the ESDPT mechanism. This work, together with our previous work in the gas phase [57], is expected to give a conclusive description of the ESDPT mechanism in 7AI dimer. 


\section{Computational Details}

Equilibrium geometries in the $\mathrm{S}_{0}$ state were optimized by the density functional theory (DFT) method using the CAM-B3LYP functional [61]. The equilibrium geometries in the $\mathrm{S}_{1}$ state were optimized by the time-dependent DFT (TDDFT) method (referred to as TD-CAMB3LYP). DFT/TDDFT calculations were performed with GAMESS [62], using 6-31G* basis sets. CAM-B3LYP is a range-separated functional and thus can well describe the energy of CT states of 7AI dimer, which is crucial for a proper description of the potential energy profiles for ESDPT in 7AI dimer [57]. We used the default parameter of CAM-B3LYP functional in GAMESS. The solvent effect was included by the conductor-like polarizable continuum model (C-PCM) [63,64], using the default parameters in GAMESS for non-polar solvents (heptane, cyclohexane and benzene) and some polar solvents (chloroform, methanol and water) and manually set parameters for other polar solvents (diethyl ether, dichloromethane and acetonitrile): the PCM parameters are shown in Table S1 in the ESI. Among these solvents, heptane, dichloromethane, chloroform, and acetonitrile were used in the experiment [46]. The equilibrium solvent effect was included not only in geometry optimization, but also in calculations of the constrained minimum energy path (cMEP) in the LE state or in the CT state. The dimerization energy for 7AI in solutions, and the solvation energies for the 7AI monomer and dimer were also calculated. For all the stationary points optimized with and without solvent effects, normal mode analysis was performed in order to verify their geometrical feature as minimum or a transition state, as well as to calculate a zero-point vibrational energy (ZPE). The energy profiles along the cMEP in the LE state were recalculated including non-equilibrium solvent effects using a PCM scheme, based on the cMEP in the $\mathrm{S}_{0}$ state in the gas phase. Vertical excitation and emission energies were also calculated with TD-CAM-B3LYP and TD-B3LYP methods at CAM-B3LYP (excitation) and TD-CAM-B3LYP (emission) optimized geometries, including non-equilibrium solvent effects.

The cMEPs in the LE and CT states were determined with the TD-CAM-B3LYP method where one internal coordinate was assumed as a reaction coordinate, and all other coordinates were optimized for the respective electronic states. Figure 1 shows a definition of the reaction coordinates for proton transfer, $M_{1}, M_{2}$ and $Q$, which were introduced in a previous report [57]. For each reaction path involving the $\mathrm{CT}$ state, the highest energy point calculated in the scan of 
cMEP was regarded as an approximate transition state $\left(\mathrm{TS}_{\mathrm{CT}}\right)$. For the reaction path in the LE state, a first-order saddle point was located as the transition state $\left(\mathrm{TS}_{\mathrm{LE}}\right)$, and IRC calculations were performed by the Gonzales-Schlegel second order algorithm with a stride of $0.3 \mathrm{amu}^{1 / 2} \mathrm{bohr}$, to confirm the connectivity of two minima and $\mathrm{TS}_{\mathrm{LE}}$.

To examine the effect of the diffuse function on the ESDPT behavior, we also calculated cMEPs in the LE state in a solution with cyclohexane and with water as solvent at the TD-CAMB3LYP/6-31+G* level. The calculated potential energy curves, shown in Fig. S1 in the ESI, do not change so much compared with those calculated at the TD-CAM-B3LYP/6-31G* level, which means that the diffusion function plays a minor role in this system. 


\section{Results and Discussion}

\subsection{Equilibrium Geometries and Excitation Energies}

In the $\mathrm{S}_{0}$ state, equilibrium structures of normal dimer $\left(\mathrm{ND}_{\mathrm{S} 0}\right)$ and tautomer dimer $\left(\mathrm{TD}_{\mathrm{S} 0}\right)$ are shown to have $\mathrm{C}_{2 h}$ symmetry in the gas phase and in solutions with non-polar and polar solvents. The optimized geometries of $\mathrm{ND}_{\mathrm{S} 0}$ and $\mathrm{TD}_{\mathrm{S} 0}$ in the gas phase (see Fig. $\mathbf{S 2}$ in the ESI) are consistent with previous calculations at the MP2 level [57].

Similar to the case in the gas phase, the $\mathrm{S}_{1}$ state for ND and TD in solutions is characterized as LE state. Figure 2a and $\mathbf{b}$ show the equilibrium structures of ND and TD in the LE state, referred to as $\mathrm{ND}_{\mathrm{LE}}$ and $\mathrm{TD}_{\mathrm{LE}}$, respectively, optimized at the TD-CAM-B3LYP/PCM level in non-polar solvent heptane. For comparison, the equilibrium structures $\mathrm{ND}_{\mathrm{LE}}$ and $\mathrm{TD}_{\mathrm{LE}}$ in the gas phase optimized at the TD-CAM-B3LYP level are shown in Fig. S3a and $\mathbf{b}$ in the ESI. Geometrical parameters do not differ so much in heptane compared to those in the gas phase. Similar results were obtained for the equilibrium structures in solutions with other non-polar and polar solvents. We note that the equilibrium structures of $\mathrm{ND}_{\mathrm{LE}}$ and $\mathrm{TD}_{\mathrm{LE}}$ optimized at the TDCAM-B3LYP level are very similar with those optimized at the CASPT2 level in the gas phase [57], although hydrogen bond distances were slightly enlarged in TD-CAM-B3LYP calculations.

All optimized geometries of $\mathrm{ND}_{\mathrm{LE}}$ and $\mathrm{TD}_{\mathrm{LE}}$ in the $\mathrm{S}_{1}$ state exhibit the $\mathrm{C}_{s}$ symmetry due to HOMO-LUMO $\pi \pi^{*}$ excitation at one monomer, see Figure 3a and $\mathbf{b}$. The excited monomer (indicated by bracket and star in Figure 2a and $\mathbf{b}$ ) is referred to as Monomer-e while the other monomer is referred to as Monomer-g. The geometry of Monomer-e is largely deviated by excitation, while Monomer-g almost keeps the ground-state geometry.

Figure 2c shows the optimized structure of single-proton-transferred intermediate, referred to as $\mathrm{INT}_{\mathrm{CT}}$ in the $\mathrm{S}_{1}$ state in heptane. The electronic state at INT $_{\mathrm{CT}}$ is a charge transfer state where an electron is transferred from HOMO of the proton-donating monomer to LUMO of the proton-accepting monomer, see Figure 3c. Thus, the $\mathrm{INT}_{\mathrm{CT}}$ structure can be regarded as a neutral intermediate where the positive charge of the proton-accepting monomer is compensated by electron transfer from the proton-donating monomer. The $\mathrm{N} \cdots \mathrm{H}$ distances of the hydrogenbonded $\mathrm{N}-\mathrm{H} \cdots \mathrm{N}$ part ( $r_{2}$ and $r_{4}$, see Figure 1) are 2.053 and $2.096 \AA$, considerably shortened by 0.2-0.3 $\AA$ compared to the ones calculated in the gas phase [57]. This result suggests the 
enhancement of the strength of the hydrogen bonds. The structures of INT $_{\mathrm{CT}}$ are similar in solutions with non-polar and polar solvents.

In polar solvents, another equilibrium structure corresponding to a single-protontransferred intermediate has also been located in the $\mathrm{S}_{1}$ state of LE character. Figure 2d shows the optimized structure of this intermediate in acetonitrile, referred to as INT $\mathrm{LE}_{\mathrm{LE}}$ Similar intermediate structures have been located in solutions with relatively large dielectric constant solvents (dichloromethane, methanol and water). Note that this structure could not be found in the gas phase and in solutions of non-polar and the smaller dielectric constant solvents (diethyl ether and chloroform). Although we attempted geometry optimization starting from $Q=0$ with these solvents, molecular structure was optimized to $\mathrm{TD}_{\mathrm{LE}}$ in all attempts.

The intermediate structure in the LE state (INT $\mathrm{LE}_{\mathrm{L}}$ ) exhibits a zwitterionic character with a local excitation on the proton donor (see Figure 3d for frontier orbitals), in contrast to the neutral intermediate $\mathrm{INT}_{\mathrm{CT}}$. In addition, a large distinction was found in geometrical parameters: $\mathrm{N} \cdots \mathrm{H}$ hydrogen bond distances are 1.703 and $1.623 \AA$ at $\mathrm{INT}_{\mathrm{LE}}$, which are much smaller than 2.053 and $2.096 \AA$ at INT $_{\mathrm{CT}}$. Comparatively, the smaller distance in hydrogen bonds at $\mathrm{INT}_{\mathrm{LE}}$ may facilitate the proton transfer in the strengthened hydrogen bonds compared to the longer distance at $\mathrm{INT}_{\mathrm{CT}}$.

Table 1 shows the relative energies of excited-state minima and TS's (relative to NDLE) in the gas phase and in solutions, with and without including ZPE. The following discussions are based on the electronic energy without ZPE, except specific notification. The relative energy of $\mathrm{TD}_{\mathrm{LE}}$ is influenced by the polarity of solvent. In the gas phase, the energy of TD $\mathrm{LE}_{\mathrm{LE}}$ calculated to be $-8.16 \mathrm{kcal} / \mathrm{mol}$ relative to $\mathrm{ND}_{\mathrm{LE}}$. This energy is considerably raised up in nonpolar solvents and in polar solvents, with the latter going up more evidently. For example, the energy of $\mathrm{TD}_{\mathrm{LE}}$ is raised to -7.03 and $-5.53 \mathrm{kcal} / \mathrm{mol}$ in heptane and acetonitrile, respectively. The inclusion of ZPE slightly increases the corresponding values as -6.10 and $-4.42 \mathrm{kcal} / \mathrm{mol}$ in heptane and acetonitrile, respectively.

The energy of the intermediate in the $\mathrm{CT}$ state is considerably influenced by the polarity of solvent. For example, the relative energy of $\mathrm{INT}_{\mathrm{CT}}$ is raised up from $-28.81 \mathrm{kcal} / \mathrm{mol}$ in the gas phase to $-15.18 \mathrm{kcal} / \mathrm{mol}$ in a solution with non-polar solvent heptane, and to $-0.52 \mathrm{kcal} / \mathrm{mol}$ with polar solvent acetonitrile, see Table 1. In the LE state, the intermediate $\mathrm{INT}_{\mathrm{LE}}$ appears when 
the dielectric constant is 8.93 (dichloromethane) or larger. The relative energy of $\mathrm{INT}_{\mathrm{LE}}$ is slightly influenced by the polarity of solvent, which was calculated to be 4.19, 4.02, 4.02 and $3.98 \mathrm{kcal} / \mathrm{mol}$ in dichloromethane, methanol, acetonitrile, and water, respectively. The relative energies of both $\mathrm{INT}_{\mathrm{CT}}$ and $\mathrm{INT}_{\mathrm{LE}}$ increase when considering the ZPE.

The dipole moment in the excited state of 7AI dimer considerably changes along the reaction path of ESDPT, as shown in Table 1 (values in parentheses). In acetonitrile, for example, the dipole moment of $\mathrm{ND}_{\mathrm{LE}}$ and $\mathrm{TD}_{\mathrm{LE}}$ was calculated to be 5.13 and 5.24 Debye, respectively. The intermediates INT ${ }_{\mathrm{CT}}$ and INT $_{\mathrm{LE}}$ exhibit much larger values of the dipole moment, 13.92 and 10.86 Debye, respectively. The same trend is found in the gas phase and in solutions with other solvents. This trend is also consistent with the previous work by Serrano-Andrés and Merchán at the PMCAS-CI/MS-CASPT2 level [56].

Table 2 summarizes vertical excitation energies at the equilibrium geometry in the $\mathrm{S}_{0}$ state and vertical emission energies at the equilibrium geometries in the $\mathrm{S}_{1}$ state at both TDCAM-B3LYP and TD-B3LYP levels. The vertical excitation energies at $\mathrm{ND}_{\mathrm{S} 0}$ in solutions are 4.83-4.84 eV with non-polar solvents (heptane, cyclohexane and benzene) and 4.84-4.86 eV with polar solvents (diethyl ether, chloroform, dichloromethane, methanol, acetonitrile and water), similar to $4.85 \mathrm{eV}$ in the gas phase at the TD-CAM-B3LYP level. The corresponding values at the TD-B3LYP level are 4.45-4.46 eV in both gas and solution phases. We note that the TD-CAM-B3LYP results are slightly overestimated, and the TD-B3LYP results are very consistent with the experimental absorption spectra in non-polar solvents [45,48] and our previous TDDFT calculations in the gas phase using the LC-BLYP functional [57]. Vertical emission energies at $\mathrm{ND}_{\mathrm{LE}}$ are $3.94 \mathrm{eV}(3.90-3.93 \mathrm{eV})$ with non-polar (polar) solvents, and those at $\mathrm{TD}_{\mathrm{LE}}$ are $2.87-2.88 \mathrm{eV}(2.91-2.95 \mathrm{eV})$ at the TD-CAM-B3LYP level. The values at ND become $3.60 \mathrm{eV}(3.63-3.66 \mathrm{eV})$ with non-polar (polar) solvents, and those at TDLE are 2.59-2.60 $\mathrm{eV}(2.64-2.69 \mathrm{eV})$ at the TD-B3LYP level. Again, the TD-B3LYP results are very consistent with the fluorescence band maximum of ND and TD in non-polar solvents $[45,48]$ as well as our previous calculations in the gas phase [57].

We also calculated the absorption and emission energies in hexane. The absorption energy at $\mathrm{ND}_{\mathrm{S} 0}$ as well as emission energies at $\mathrm{ND}_{\mathrm{LE}}$ and $\mathrm{TD}_{\mathrm{LE}}$ are 4.84, 3.95 and $2.87 \mathrm{eV}$, respectively, at the TD-CAM-B3LYP level. The corresponding values are 4.45, 3.60 and $2.58 \mathrm{eV}$, 
respectively, at the TD-B3LYP level. These results are very similar to the ones with other nonpolar solvents. The error is within $0.15 \mathrm{eV}$ from experimental results $(4.32 \mathrm{eV}$ for absorption and $2.53 \mathrm{eV}$ for fluorescence [45], see Table 2) using TD-B3LYP functional. The relatively large error of $0.5 \mathrm{eV}$ from experimental results using TD-CAM-B3LYP is due to the increased proportion of an exact exchange energy in this functional, which aims to reduce the errors in excitation energy of CT and Rydberg states. While, the vertically excited $\mathrm{S}_{1}$ state at NDso and the $\mathrm{S}_{1}$ state at $\mathrm{ND}_{\mathrm{LE}}$ and $\mathrm{TD}_{\mathrm{LE}}$ in $7 \mathrm{AI}$ dimer in solutions is local excitation.

For the intermediate in the CT state $\left(\mathrm{INT}_{\mathrm{CT}}\right)$, the energy difference between $\mathrm{S}_{1}$ and $\mathrm{S}_{0}$ in the gas phase was calculated to be $1.01 \mathrm{eV}$ (see Table 2), which is very similar to the one calculated by Barbatti and co-workers [60]. This result suggests that the internal conversion from $\mathrm{INT}_{\mathrm{CT}}$ is likely to occur in the gas phase, as predicted by on-the-fly dynamics simulations [60]. However, in solution, the energy difference has been found much larger, see Table 2. In nonpolar solvent heptane, it was calculated to be $2.14 \mathrm{eV}$. Similar values were calculated at INTCT with other non-polar solvents. The energy gap is even larger with polar solvents, such as $3.10 \mathrm{eV}$ in acetonitrile. These findings indicate that the nonradiative decay is less possible to occur in solutions than in the gas phase.

The energy gap between $\mathrm{S}_{1}$ and $\mathrm{S}_{0}$ at the intermediate in the LE state (INT $\mathrm{LE}_{\text {) }}$ in solutions with polar solvents is also shown in Table 2 . In acetonitrile, the energy gap was calculated to be $3.40 \mathrm{eV}$ at $\mathrm{INT}_{\mathrm{LE}}$, which is $c a .0 .3 \mathrm{eV}$ larger than that at $\mathrm{INT}_{\mathrm{CT}}$. Similar values were also obtained for other polar solvents (dichloromethane, methanol, and water). The relatively large values are likely to prevent the nonradiative decay through LE state in solutions with polar solvents.

Table 2 also shows the oscillator strength calculated at each minimum. The oscillator strength at $\mathrm{ND}_{\mathrm{LE}}$ is similar to that at $\mathrm{ND}_{\mathrm{S} 0}$, while $\mathrm{TD}_{\mathrm{LE}}$ exhibits the smaller value. In acetonitrile, for example, the oscillator strength for $\mathrm{ND}_{\mathrm{LE}}$ and $\mathrm{TD}_{\mathrm{LE}}$ was calculated to be 0.210 and 0.058 , respectively, while, for $\mathrm{INT}_{\mathrm{CT}}$ and $\mathrm{INT}_{\mathrm{LE}}$, the calculated values are 0.005 and 0.106 , respectively. Similar values were calculated for other polar solvents. The values at $\mathrm{INT}_{\mathrm{LE}}$ may be enough for relatively strong emission from the intermediate. However, as discussed in next section, once $\mathrm{INT}_{\mathrm{LE}}$ is formed, the second proton transfer toward $\mathrm{TD}_{\mathrm{LE}}$ is expected to occur very quickly with a low energy barrier. Therefore, the fluorescence from $\mathrm{INT}_{\mathrm{LE}}$ is likely unfeasible to occur. 
The 7AI dimerization energies in the gas phase and in solutions, and solvation energies for $7 \mathrm{AI}$ dimer $\left(\mathrm{ND}_{\mathrm{S} 0}\right)$ and monomer were calculated at the CAM-B3LYP/6-31G* level in the $\mathrm{S}_{0}$ state, as shown in Table 3. The dimerization energy was estimated as a difference of the energy of $\mathrm{ND}_{\mathrm{S} 0}$ and the energy of two monomers located far away from each other (the distance of C8C8' is fixed to $10.2 \AA$ ), while the solvation energies were calculated as a difference of the energy in a solution and that in the gas phase. As the dielectric constant of the solvent increases, the dimerization energy decreases and the solvation energies for both dimer and monomer increase. Since 7AI dimerization energies in solutions are larger than the corresponding solvation energy of 7AI monomer for all solvents, 7AI dimerization is expected to occur in solutions. The 7AI dimerization in acetonitrile, heptane, chloroform and dichloromethane was reported in experimental studies $[46,65]$. In the case of protic solvents such as methanol and water, however, the 7AI dimerization may be affected largely due to a hydrogen bonding between 7AI and solvent molecules, but this is out of scope of the present work.

\subsection{Reaction Path of ESDPT in the Locally-Excited State}

In all non-polar solvents (heptane, cyclohexane, and benzene) and some polar solvents (diethyl ether and chloroform), no intermediate was found in the LE state as well as in the gas phase, and one transition state has been located at the structure where Monomer-e is releasing the proton of the NH bond. Figure 4a shows the optimized transition state geometry in the LE state, referred to as $\mathrm{TS}_{\mathrm{LE}}$, in heptane. At this structure, one proton is just transferred along the $\mathrm{N}-\mathrm{H} \cdots \mathrm{N}$ hydrogen bond from Monomer-e to Monomer-g, while the other proton is still bound to a fivemembered ring of Monomer-g $\left(Q=-0.22 \AA, M_{1}=0.13 \AA, M_{2}=-0.57 \AA\right)$. This finding suggests that $\mathrm{TS}_{\mathrm{LE}}$ is a transition state for asynchronous proton transfer. Similar geometry was located as $\mathrm{TS}_{\mathrm{LE}}$ for other non-polar solvents (cyclohexane and benzene) and polar solvents (diethyl ether and chloroform).

In solutions with other polar solvents (dichloromethane, acetonitrile, methanol, and water), the INT $\mathrm{IE}_{\mathrm{LE}}$ structure was found, and two transition states were located where both transferred protons are closer to Monomer-g than Monomer-e. Figure $\mathbf{4 b}$ and $\mathbf{4 c}$ show the optimized transition state geometries, referred to as $\mathrm{TS}_{\mathrm{LE} 1}$ and $\mathrm{TS}_{\mathrm{LE} 2}$, in acetonitrile. At each transition state, one proton is lying in the middle site of the hydrogen bond, while the other 
proton is located on Monomer-g. At $\operatorname{TS}_{\mathrm{LE} 1}\left(Q=-0.29 \AA, M_{1}=0.09 \AA, M_{2}=-0.67 \AA\right)$, one proton is located in the middle of the hydrogen bond $\mathrm{N} 1^{\prime}-\mathrm{H} 10^{\prime} \cdots \mathrm{N} 7$, while the other proton remains at the five-membered ring of Monomer-g. At $\mathrm{TS}_{\mathrm{LE} 2}\left(Q=0.21 \AA, M_{1}=0.69 \AA, M_{2}=-\right.$

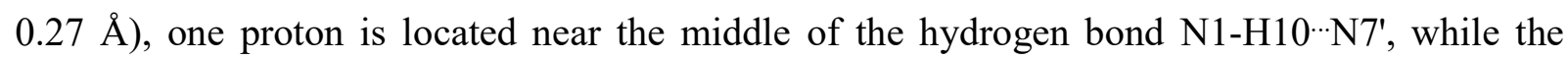
other proton is transferred to the six-membered ring of Monomer-g. The optimized TS $\mathrm{LE1}_{1}$ and $\mathrm{TS}_{\mathrm{LE2}}$ geometries in dichloromethane, methanol, and water are very similar to the ones in acetonitrile.

To examine the equilibrium solvent effect on the ESDPT mechanism in more detail, we calculated the cMEPs of 7AI dimer in the LE state along the reaction coordinate $Q$. Figure 5 shows potential energy profiles for ESDPT in solutions with non-polar solvents (heptane, cyclohexane, and benzene). The shapes of the potential energy profiles are very similar to each other and to the one in the gas phase calculated with CASPT2 and TDDFT in our previous work [57]. We also calculated the potential energy profiles in the gas phase at the TD-CAM-BLYP level. The calculated profile, shown in Fig. S4 in the ESI, is very similar to the one in the gas phase calculated with CASPT2 and TDDFT in our previous work [57], also with the ones in solutions with non-polar solvents, which further confirm that the current computational method can qualitatively describe the ESDPT process in 7AI dimer in solutions. In the gas phase and in solutions with non-polar solvents, the $\mathrm{S}_{1}$ state is dominated by the LE configuration all along the reaction path.

In Fig. 5, only one maximum was found for each potential energy profile and no zwitterionic intermediate was located. The maximum point near $Q=-0.2 \AA$ corresponds to $\mathrm{TS}_{\mathrm{LE}}$, while two minima at $Q=-0.77$ and $0.83 \AA$ correspond to $\mathrm{ND}_{\mathrm{LE}}$ and $\mathrm{TD}_{\mathrm{LE}}$, respectively. This result suggests that ESDPT of 7AI dimer in solutions with non-polar solvents (heptane, cyclohexane, and benzene) follows the concerted mechanism in the LE state. The IRC calculations starting from $\mathrm{TS}_{\mathrm{LE}}$ also exhibited the connectivity with $\mathrm{ND}_{\mathrm{LE}}$ and $\mathrm{TD}_{\mathrm{LE}}$, which supports the concerted mechanism. Considering the similar dielectric constant of hexane with the other non-polar solvents (heptane, cyclohexane, and benzene), we expect the cMEP in hexane is also similar with those in solutions with other non-polar solvents, exhibiting the concerted mechanism. 
Figure 6 shows potential energy profiles in the lowest 6 excited states in heptane. At the ND structure, the lowest four excited states are LE states, and the fifth excited state is a CT character. The $\mathrm{S}_{1}$ state is dominated by the LE configurations through the proton transfer process. In a region of $Q=-0.3 \sim 0.2 \AA$, however, one $\mathrm{CT}$ state is rapidly stabilized, resulting in change of the character of the $\mathrm{S}_{2}$ state from LE to CT. The smallest energy gap of CT and LE states at $Q$ $=0$ is $0.11 \mathrm{eV}$ in heptane. The same feature can also be found in solutions with other solvents, as shown in Fig. S5a-h in the ESI.

The non-equilibrium solvent effect was also investigated in the ESDPT process in the LE state. Fig. S6 in the ESI shows the potential energy profiles for the ESDPT in non-polar solvents (heptane, cyclohexane, and benzene) as a function of $Q$ along the pathway determined for the ground state in the gas phase. The potential energy profiles in solutions with non-polar solvents are very similar with each other. The energy barrier considering the non-equilibrium solvent effect, shown in Table S2 in the ESI, is about $0.8 \mathrm{kcal} / \mathrm{mol}$ higher than the one including the equilibrium solvent effect, indicating that the difference of non-equilibrium and equilibrium solvent effects are very small.

Table 1 also shows the electronic energy of transition state structures relative to NDLE. The height of a potential energy barrier, estimated by the energy difference between $\mathrm{ND}_{\mathrm{LE}}$ and $\mathrm{TS}_{\mathrm{LE}}$, is $6.06,6.04$ and $6.04 \mathrm{kcal} / \mathrm{mol}$ in heptane, cyclohexane, and benzene, respectively, without ZPE. These barriers are slightly lower than that in the gas phase, $6.13 \mathrm{kcal} / \mathrm{mol}$ at the TD-CAM-B3LYP level. By including ZPE, the barrier is largely reduced to 2.73, 2.74 and 2.76 $\mathrm{kcal} / \mathrm{mol}$ in heptane, cyclohexane and benzene, respectively. The dipole moments were calculated to be 7.12, 7.18 and 7.30 Debye in heptane, cyclohexane and benzene, respectively, which are larger than 5.94 Debye in the gas phase.

The potential energy profiles of the ESDPT processes in solutions with polar solvents, diethyl ether, chloroform, dichloromethane, methanol, acetonitrile, and water, along $Q$ are shown in Figure 7. The shape of potential energy profiles considerably depend on the dielectric constant. The intermediate INT $\mathrm{LE}_{\mathrm{LE}}$ appears when the dielectric constant of solvent is relatively large, probably due to a strong electrostatic interaction between the solvent and the dimer with non-zero dipole moment as shown in Table 1. 
In diethyl ether and chloroform, no intermediate minimum could be located near $Q=0$, although the potential profile shows a very flat nature around $Q=0-0.2 \AA$, see Figure 7a. This result suggests that ESDPT is likely to follow the concerted mechanism when the dielectric constant of solvent is small. The barrier height at $\mathrm{TS}_{\mathrm{LE}}$ was calculated to be 5.97 and 5.95 $\mathrm{kcal} / \mathrm{mol}$ in diethyl ether and chloroform, respectively (see Table 1), which are slightly lower than the ones in the gas phase and in solutions with non-polar solvents. Including ZPE, the barrier height was reduced to 2.76 and $2.59 \mathrm{kcal} / \mathrm{mol}$ in diethyl ether and chloroform, respectively. The dipole moments were calculated to be 7.81 and 7.88 Debye in diethyl ether and chloroform, respectively, which are slightly larger than those in non-polar solvents.

In dichloromethane, methanol, acetonitrile, and water, on the other hand, there appears a shallow minimum near $Q=0$ in the reaction path, see Figure 7b. After full-optimization of the structure, we located a true minimum for the zwitterionic intermediate $\mathrm{INT}_{\mathrm{LE}}$. The energies of $\mathrm{INT}_{\mathrm{LE}}$ are 3.98-4.19 kcal/mol higher than $\mathrm{ND}_{\mathrm{LE}}$ and 9.40-10.02 kcal/mol higher than $\mathrm{TD}_{\mathrm{LE}}$ (see Table 1).

The potential energy profiles in Figure $7 \mathrm{~b}$ exhibit two energy barriers near $Q=-0.3$ and $0.2 \AA$. The first and second barriers correspond to $\mathrm{TS}_{\mathrm{LE} 1}$ and $\mathrm{TS}_{\mathrm{LE} 2}$, respectively. $\mathrm{TS}_{\mathrm{LE} 1}$ is a transition state for the first proton transfer from $\mathrm{ND}_{\mathrm{LE}}$ to $\mathrm{INT}_{\mathrm{LE}}$, while $\mathrm{TS}_{\mathrm{LE} 2}$ is for the second proton transfer from $\mathrm{INT}_{\mathrm{LE}}$ to $\mathrm{TD}_{\mathrm{LE}}$. The connections of these stationary points were also confirmed by the IRC calculations starting with each TS structure. The findings above suggest that in dichloromethane, methanol, acetonitrile, and water, two protons are transferred sequentially with the stepwise mechanism, forming an intermediate after the first proton transfer. In this mechanism, ESDPT occurs in the LE state without involving CT states.

The barrier height for the first proton transfer was estimated to be $5.88-5.94 \mathrm{kcal} / \mathrm{mol}$ (with respect to $\mathrm{ND}_{\mathrm{LE}}$ ), while that for the second proton transfer was $0.06-0.21 \mathrm{kcal} / \mathrm{mol}$ (with respect to $\mathrm{INT}_{\mathrm{LE}}$ ). This result suggests that the first proton transfer is the rate-determining step in the stepwise ESDPT. Including the ZPE, however, the relative energies of both transition states $\mathrm{TS}_{\mathrm{LE} 1}$ and $\mathrm{TS}_{\mathrm{LE} 2}$ decrease significantly, and become even lower than the energy of INT $_{\mathrm{LE}}$, shown in Table 1. This result indicates that the stepwise reaction path turns out to be concerted reaction path even in solutions with polar solvents when considering ZPE at stationary points. The relative energies of $\mathrm{INT}_{\mathrm{LE}}$ and $\mathrm{TS}_{\mathrm{LE} 1}$ are not so large $(0.4 \sim 0.6 \mathrm{kcal} / \mathrm{mol})$ and a quantitative 
estimation of ZPE including the anharmonicity will possibly change the energetics, but anyway the region of $\mathrm{TS}_{\mathrm{LE} 1} \sim \mathrm{INT}_{\mathrm{LE}} \sim \mathrm{TS}_{\mathrm{LE} 2}$ should be very flat, and ESDPT should proceed with the almost concerted (but asynchronous) mechanism. The calculated dipole moments at $\mathrm{TS}_{\mathrm{LE} 1}$ are 8.11-8.37 Debye in solutions of polar solvents with the larger dielectric constant, which are 1.041.24 Debye lower than those at $\mathrm{TS}_{\mathrm{LE} 2}$. Combined with the calculated dipole moments at $\mathrm{TS}_{\mathrm{LE}}$ in solutions of non-polar solvents and polar solvents with the smaller dielectric constant, it is very interesting to note that the energy barrier decreases against the increase in dipole moment at $\mathrm{TS}_{\mathrm{LE}}$, $\mathrm{TS}_{\mathrm{LE} 1}$ and $\mathrm{TS}_{\mathrm{LE} 2}$.

The non-equilibrium solvent effect from polar solvents was also examined for ESDPT in the LE state. In the ESI, potential energy profiles for ESDPT in solutions with polar solvents (diethyl ether, chloroform, dichloromethane, methanol, acetonitrile, and water) along $Q$ are shown in Fig. S7a and S7b. The potential energy profiles with non-equilibrium solvent effects of polar solvents are very similar with each other, and an intermediate appears along the reaction path in all cases. The energy barriers with non-equilibrium solvent effects are about 0.5-0.8 $\mathrm{kcal} / \mathrm{mol}$ higher than the ones considering equilibrium solvent effect (Table S2 in the ESI), but their energy profiles are basically unchanged.

For all solvents, we located another transition state structure in solutions where both transferred protons are closer to Monomer-e than Monomer-g, which is in contrast to $\mathrm{TS}_{\mathrm{LE}}$, $\mathrm{TS}_{\mathrm{LE} 1}$, and $\mathrm{TS}_{\mathrm{LE} 2}$ where the protons are closer to Monomer-g than Monomer-e. The optimized structure, labeled as $\mathrm{TS}_{\mathrm{Mix}}$, in acetonitrile is shown in Figure 4d. At $\operatorname{TS}_{\mathrm{Mix}}\left(Q=-0.24 \AA, M_{1}=-\right.$ $0.62 \AA, M_{2}=0.13 \AA$ ), one proton is located near the middle site of the hydrogen bond and closer to Monomer-e, while the other proton remains on Monomer-e. It was verified that the proton is transferred from Monomer-g to Monomer-e, where Monomer-e is the proton acceptor. The asymmetry of hydrogen-bond structure suggests that $\mathrm{TS}_{\mathrm{Mix}}$ is also a transition state for asynchronous proton transfer. The character of the $\mathrm{S}_{1}$ state at $\mathrm{TS}_{\mathrm{Mix}}$ is dominated by local excitation on the proton acceptor and mixed with small part of charge transfer from Monomer-g to Monomer-e. The optimized TS $\mathrm{Six}_{\mathrm{x}}$ geometries in the gas phase and with other solvents are very similar to the one in acetonitrile.

Figure 8 shows potential energy profiles along the IRC paths through $\mathrm{TS}_{\mathrm{Mix}}$ in solutions. The IRC calculation shows that the transition state directly connects $\mathrm{ND}_{\mathrm{LE}}$ and $\mathrm{TD}_{\mathrm{LE}}$ in non- 
polar solvent benzene and all polar solvents (Figure 8a), while it connects $\mathrm{ND}_{\mathrm{LE}}$ and $\mathrm{INT}_{\mathrm{CT}}$ in other non-polar solvents (heptane and cyclohexane) (Figure 8b). This result suggests that ESDPT along the reaction path through $\mathrm{TS}_{\mathrm{Mix}}$ follows the asynchronous concerted mechanism in solutions with solvents other than heptane and cyclohexane. The different connection of the IRC path may be due to the distinction of the electronic character in these transition states. In heptane and cyclohexane, the extent of charge transfer character is larger than that with other solvents.

Along the IRC paths starting at $\mathrm{ND}_{\mathrm{LE}}$ through $\mathrm{TS}_{\mathrm{Mix}}$, the monomers approach each other first with energy increasing gradually, followed by a sharp increase of the energy because of a single proton transfer from Monomer-g to Monomer-e until reaching $\mathrm{TS}_{\mathrm{Mix}}$. After that the energy decreases gradually when the two protons are on the same site, followed by a very sharp decrease of the energy due to the completion of proton transfer toward TDLE or INTCT. For all solvents other than heptane and cyclohexane, the IRC calculations show that there is no intermediate minimum along the reaction path, although there is a flat region (see Figure 8a). We note that in this reaction path the first proton transfer occurs from Monomer-g to Monomer-e, while it occurs from Monomer-e to Monomer-g in other reaction paths through $\mathrm{TS}_{\mathrm{LE}}$ or through $\mathrm{TS}_{\mathrm{LE} 1}$ and $\mathrm{TS}_{\mathrm{LE} 2}$.

The energy barrier at $\mathrm{TS}_{\text {Mix }}$ was calculated to be $7.00-7.24 \mathrm{kcal} / \mathrm{mol}$ in solutions with solvents studied, which is $0.94-1.36 \mathrm{kcal} / \mathrm{mol}$ higher than the one at $\mathrm{TS}_{\mathrm{LE}}$ and $\mathrm{TS}_{\mathrm{LE} 1}$, see Table 1. Therefore, the proton transfer through $\mathrm{TS}_{\mathrm{Mix}}$ is less likely to occur than the concerted ESDPT through $\mathrm{TS}_{\mathrm{LE}}$ or the stepwise ESDPT through $\mathrm{TS}_{\mathrm{LE} 1}$ and $\mathrm{TS}_{\mathrm{LE} 2}$ in each solvent. Including ZPE, the energy barrier at $\mathrm{TS}_{\mathrm{Mix}}$ is still higher than $\mathrm{TS}_{\mathrm{LE}}$ and $\mathrm{INT}_{\mathrm{LE}}$, and thus, ESDPT is also likely to follow the concerted mechanism. The dipole moments at $\mathrm{TS}_{\mathrm{Mix}}$ in non-polar solvents, heptane, cyclohexane, and benzene, are 5.86, 5.92, and 6.06 Debye, respectively, and those in polar solvents, diethyl ether, chloroform, dichloromethane, methanol, acetonitrile and water, are 6.61, $6.68,6.93,7.16,7.17$ and 7.21 Debye, respectively. This result shows that the energy increase of $\mathrm{TS}_{\mathrm{Mix}}$ is correlated with the increase of the dipole moment against dielectric constant of solvent, contrary to the case of other TS structures.

The potential energy profiles in the LE state suggest that the ESDPT mechanism can change depending on the polarity of the solvent. In solutions with non-polar and the smaller dielectric constant solvents, the potential energy profile and reaction mechanism in the LE state 
do not change so much from those in the gas phase considering the equilibrium solvent effect. However, in solutions with the larger dielectric constant solvents, the formation of an intermediate in the LE state is evident, changing the mechanism from that in the gas phase. Under the non-equilibrium solvent effect, the intermediate remains with all polar solvents (see Fig. S7a and $7 b$ in the ESI), indicating the stepwise mechanism. While including ZPE, the concerted mechanism seems to be maintained in solutions with all solvents.

\subsection{Reaction Path in the Charge-Transfer State}

To unveil the proton transfer mechanism in the $\mathrm{CT}$ state, we also calculated the cMEPs for proton transfers from $\mathrm{ND}_{\mathrm{LE}}$ to $\mathrm{INT}_{\mathrm{CT}}$ and from $\mathrm{INT}_{\mathrm{CT}}$ to $\mathrm{TD}_{\mathrm{LE}}$ in solutions with all solvents. The calculated cMEPs with non-polar solvents (heptane, cyclohexane, and benzene) are shown in Figure 9. In the first proton transfer process, the energy gradually increases before reaching the highest energy point (referred to as $\mathrm{TS}_{\mathrm{CT} 1}$ ), followed by a sudden decrease in energy from $\mathrm{TS}_{\mathrm{CT} 1}$ toward $\mathrm{INT}_{\mathrm{CT}}$. The energy barrier for this process was estimated to be $9.1,9.5$ and 10.3 $\mathrm{kcal} / \mathrm{mol}$ in heptane, cyclohexane, and benzene, respectively. This barrier lies higher in energy than the barrier at $\mathrm{TS}_{\mathrm{LE}}$ with all non-polar solvents. Once $\mathrm{INT}_{\mathrm{CT}}$ is formed, the second proton transfer can occur if the dimer overcomes the energy barrier at the second TS (referred to as $\mathrm{TS}_{\mathrm{CT} 2}$ ), which were estimated to be $20.7,20.4$ and $20.0 \mathrm{kcal} / \mathrm{mol}$. The reverse proton transfer from $\mathrm{TD}_{\mathrm{LE}}$ to $\mathrm{INT}_{\mathrm{CT}}$ is also possible due to the relatively low energy barrier of 12.5, 13.0 and $13.8 \mathrm{kcal} / \mathrm{mol}$ and the relatively low energy of $\mathrm{INT}_{\mathrm{CT}}$.

Figure 10 shows the cMEPs for the first and second proton transfer processes in solutions with polar solvents. In acetonitrile, the energy barriers at $\mathrm{TS}_{\mathrm{CT} 1}$ and $\mathrm{TS}_{\mathrm{CT} 2}$ were estimated to be 7.0 and $11.1 \mathrm{kcal} / \mathrm{mol}$, respectively. This finding suggests that the second proton transfer process is the rate-determining step of ESDPT via the CT state in acetonitrile. The back proton transfer from $\mathrm{TD}_{\mathrm{LE}}$ to $\mathrm{INT}_{\mathrm{CT}}$ is more difficult to occur than in non-polar solvents due to the high energy barrier of $16.1 \mathrm{kcal} / \mathrm{mol}$ and the relatively high energy of INTCT. The intermediate $\mathrm{INT}_{\mathrm{CT}}$ lies much higher in energy than $\mathrm{TD}_{\mathrm{LE}}$, making the second proton transfer process thermodynamically feasible. $\mathrm{TD}_{\mathrm{LE}}$ can be formed if excitation energy is high enough to overcome the total energy barrier at $\mathrm{TS}_{\mathrm{CT} 2}$. Otherwise, the dimer remains around $\mathrm{INT}_{\mathrm{CT}}$ even if passing over the energy barrier at $\mathrm{TS}_{\mathrm{CT} 1}$. 
The energy profiles in methanol and water are very similar to the one in acetonitrile. Particularly, the barrier at $\mathrm{TS}_{\mathrm{CT} 2}$ is higher than the barrier at $\mathrm{TS}_{\mathrm{CT} 1}$, suggesting that the second proton transfer is the rate-determining step also in solutions with these solvents. In methanol, the energy barrier for the first and second proton transfers was estimated to be 6.9 and $11.1 \mathrm{kcal} / \mathrm{mol}$, respectively. In water, the corresponding values are 7.4 and $11.0 \mathrm{kcal} / \mathrm{mol}$, respectively.

In dichloromethane, the barrier at TS $\mathrm{T}_{\mathrm{CT} 1}$ lies higher in energy than the barrier at TS $\mathrm{TT2}$, suggesting that the first proton transfer is a rate-determining step. The energy barrier for the first and second proton transfers is estimated to be 10.6 and $8.5 \mathrm{kcal} / \mathrm{mol}$, respectively. The relative energies at the highest energy points for the first and second proton transfers $\left(\mathrm{TS}_{\mathrm{CT} 1}\right.$ and $\mathrm{TS}_{\mathrm{CT2}}$ ) are 8.3 and $5.6 \mathrm{kcal} / \mathrm{mol}$ in diethyl ether and 8.8 and $6.2 \mathrm{kcal} / \mathrm{mol}$ in chloroform, respectively, indicating the first proton transfer process to be the rate-determining step also in these solvents. The energy barrier for the second proton transfer and the reverse process exhibits similar values, thus $\mathrm{TD}_{\mathrm{LE}}$ is expected to get back to $\mathrm{INT}_{\mathrm{CT}}$ with a certain ratio if the second proton transfer process occurs.

It is worthy to mention that the electronic character at $\mathrm{TS}_{\mathrm{CT} 1}$ and $\mathrm{TS}_{\mathrm{CT} 2}$ in $\mathrm{S}_{1}$ is a $\mathrm{CT}$ state, while the electronic character in $\mathrm{S}_{2}$ state becomes LE state in heptane. The $\mathrm{S}_{2}$ state at $\mathrm{TS}_{\mathrm{CT} 1}$ and $\mathrm{TS}_{\mathrm{CT2}}$ is nearly degenerate with the $\mathrm{S}_{1}$ state (energy gap of 0.42 and $0.48 \mathrm{eV}$, respectively), exhibiting an avoided crossing between $\mathrm{S}_{1}$ and $\mathrm{S}_{2}$ states. The similar behavior can also be found in solutions with other solvents.

To reveal the relationship of the inter-monomer distance with the electronic character, we calculated the IRC path from INT $_{\mathrm{LE}}$ to $\mathrm{INT}_{\mathrm{CT}}$, where the electronic character of the transition state is a superposition of LE and CT states. Fig. S8 in the ESI shows potential energy profiles in polar solvents (dichloromethane, methanol, acetonitrile, and water) exhibiting the INT $_{\mathrm{LE}}$ structure. $\mathrm{INT}_{\mathrm{CT}}$ lies $4.1-7.4 \mathrm{kcal} / \mathrm{mol}$ lower in energy than $\mathrm{INT}_{\mathrm{LE}}$. The energy barriers for the forward and backward processes are $0.8-1.4 \mathrm{kcal} / \mathrm{mol}$ and $5.4-8.1 \mathrm{kcal} / \mathrm{mol}$, respectively. Evidently, the dimer at $\mathrm{INT}_{\mathrm{LE}}$ can go to $\mathrm{INT}_{\mathrm{CT}}$ by overcoming a low energy barrier, which opens a pathway from LE to CT states. However, this barrier is higher than that for the second proton transfer in the LE state from $\mathrm{INT}_{\mathrm{LE}}$ to $\mathrm{TD}_{\mathrm{LE}}$, see Table 1 and Figure $7 \mathrm{~b}$.

\subsection{ESDPT Mechanism of 7AI Dimer in Non-Polar and Polar Solvents}


In solutions of non-polar and the smaller dielectric constant solvents, three reaction pathways have been revealed for ESDPT in 7AI dimer.

Path I: $\mathrm{ND}_{\mathrm{LE}} \rightarrow \mathrm{TS}_{\mathrm{LE}} \rightarrow \mathrm{TD}_{\mathrm{LE}}$ (concerted mechanism)

Path II: $\mathrm{ND}_{\mathrm{LE}} \rightarrow \mathrm{TS}_{\mathrm{Mix}}\left(\rightarrow \mathrm{INT}_{\mathrm{CT}} \rightarrow \mathrm{TS}_{\mathrm{CT} 2}\right) \rightarrow \mathrm{TD}_{\mathrm{LE}}$ (concerted or stepwise mechanism)

Path III: $\mathrm{ND}_{\mathrm{LE}} \rightarrow \mathrm{TS}_{\mathrm{CT} 1} \rightarrow \mathrm{INT}_{\mathrm{CT}} \rightarrow \mathrm{TS}_{\mathrm{CT} 2} \rightarrow \mathrm{TD}_{\mathrm{LE}}$ (stepwise mechanism)

Path I is very similar to the Route I in the gas phase proposed in ref. [57]. This reaction path exhibits a single-step DPT process from $\mathrm{ND}_{\mathrm{LE}}$ to $\mathrm{TD}_{\mathrm{LE}}$ in the LE state, with no stable zwitterionic intermediate formed. ESDPT occurs asynchronously with the motions of two protons strongly correlated following the concerted mechanism.

Path II exhibits the ESDPT process through $\mathrm{TS}_{\text {Mix. }}$ In solutions with the small dielectric constant solvents (heptane and cyclohexane), the first proton transfer occurs from NDLE to INTCT, and then, the second proton transfer occurs from $\mathrm{INT}_{\mathrm{CT}}$ to $\mathrm{TD}_{\mathrm{LE}}$ (see Figure 9). When the dielectric constant is larger (benzene, diethyl ether and chloroform), Path II shows another single-step tautomerization route from $\mathrm{ND}_{\mathrm{LE}}$ to $\mathrm{TD}_{\mathrm{LE}}$, triggered by a proton transfer from Monomer-g to Monomer-e. This reaction path is different from Path I where the proton is initially transferred from Monomer-e to Monomer-g.

Path III exhibits a two-step process with the stable neutral intermediate INT $_{\mathrm{CT}}$ formed. This path is very similar to the Route II in the gas phase [57]. ESDPT via Path III occurs with the stepwise mechanism. The first proton transfer occurs along the reaction path from $\mathrm{ND}_{\mathrm{LE}}$ to $\mathrm{INT}_{\mathrm{CT}}$ through $\mathrm{TS}_{\mathrm{CT} 1}$, and then, the second proton transfer occurs along the reaction path from INT $_{\mathrm{CT}}$ to $\mathrm{TD}_{\mathrm{LE}}$ through $\mathrm{TS}_{\mathrm{CT} 2}$.

From the viewpoint of a barrier height, the single-step process via Path $\mathrm{I}$ is thermodynamically more feasible than the other processes via Path II or Path III. Thus, the ESDPT process is more likely to follow the concerted mechanism. Path II may be also accessible due to the just slightly higher energy barrier compared to Path I. This conclusion holds even when considering the ZPE at stationary points along the pathways.

In solutions with the relatively large dielectric constant solvents, the reaction path looks quite different due to a strong electrostatic interaction with the solvent. We have found three main reaction paths for tautomerization from $\mathrm{ND}_{\mathrm{LE}}$ to $\mathrm{TD}_{\mathrm{LE}}$.

Path I: $\mathrm{ND}_{\mathrm{LE}} \rightarrow \mathrm{TS}_{\mathrm{LE} 1} \rightarrow \mathrm{INT}_{\mathrm{LE}} \rightarrow \mathrm{TS}_{\mathrm{LE} 2} \rightarrow \mathrm{TD}_{\mathrm{LE}}$ (stepwise mechanism). 
Path II: ND $\mathrm{NE}_{\mathrm{LE}} \rightarrow \mathrm{TS}_{\mathrm{Mix}} \rightarrow \mathrm{TD}_{\mathrm{LE}}$ (concerted mechanism).

Path III: $\mathrm{ND}_{\mathrm{LE}} \rightarrow \mathrm{TS}_{\mathrm{CT} 1} \rightarrow \mathrm{INT}_{\mathrm{CT}} \rightarrow \mathrm{TS}_{\mathrm{CT} 2} \rightarrow \mathrm{TD}_{\mathrm{LE}}$ (stepwise mechanism).

In Path I, due to the solute-solvent interaction, the intermediate $\mathrm{INT}_{\mathrm{LE}}$ appears in the LE state. The first proton transfer is a rate-determining step, while the second proton transfer is almost a barrier-less process. The electronic character of the intermediate is a CT state through a structural transformation from INT $\mathrm{LE}_{\mathrm{LE}}$ to $\mathrm{INT}_{\mathrm{CT}}$ (Fig. S8 in the ESI), but this process is less likely to occur than the second proton transfer to $\mathrm{TD}_{\mathrm{LE}}$ because of the higher energy barrier. Including ZPE at stationary points, however, the energy at $\mathrm{INT}_{\mathrm{LE}}$ becomes higher than those at $\mathrm{TS}_{\mathrm{LE} 1}$ and $\mathrm{TS}_{\mathrm{LE} 2}$, indicating that the reaction mechanism returns to the concerted one.

In Path II, the dimer tautomerizes from $\mathrm{ND}_{\mathrm{LE}}$ to $\mathrm{TD}_{\mathrm{LE}}$ through a single-step DPT via TS $S_{\text {Mix }}$ in the LE state without forming a zwitterionic intermediate. Thus, ESDPT occurs asynchronously, following the concerted mechanism with proton transfer initiated from Momomer-g to Monomer-e.

In Path III, the intermediate $\mathrm{INT}_{\mathrm{CT}}$ is formed in the CT state as in the case of the gas phase and in solutions with non-polar and the smaller dielectric constant solvents. With the larger dielectric constant solvents, however, the energy of the CT state is highly raised up compared to the gas phase. The energy barriers at $\mathrm{TS}_{\mathrm{CT} 1}$ and $\mathrm{TS}_{\mathrm{CT} 2}$ suggest that the first proton transfer is a rate-determining step in diethyl ether, chloroform, and dichloromethane, while the second proton transfer is a rate-determining step in methanol, acetonitrile, and water.

With the larger dielectric constant solvents, Path II exhibits a single-step process without forming any intermediate, while Path I and Path III exhibit a two-step process with an intermediate formed either in the LE or CT state. In view of the energy barrier for these paths, the proton transfer is more likely to occur with the stepwise mechanism via Path I in the LE state. The proton transfer via Path II in the LE state (concerted mechanism) is also competitive with Path I, considering a slightly higher energy barrier in Path II. By including ZPE, however, both Path I and Path II exhibit a single-step process, with the former slightly more competitively.

The present calculated results in solutions with both non-polar and polar solvents are consistent with the experimental observations. With non-polar solvents, the concerted ESDPT process via Path I is supposed to be responsible for the single exponential decay of time-resolved fluorescence after the excitation at the red-edge of the $S_{1}-S_{0}$ absorption [45]. Furthermore, the 
fluorescence with the wavelength of $560 \mathrm{~nm}$, attributed to the emission from $\mathrm{TD}_{\mathrm{LE}}$, rises in accordance with the disappearance of the fluorescence of $420 \mathrm{~nm}$, assigned to the emission from $\mathrm{ND}_{\mathrm{LE}}[45]$. This result excludes the formation of the stable intermediate in the DPT process and is very consistent with Path $\mathrm{I}$ in solutions of non-polar solvents, a direct path from $\mathrm{ND}_{\mathrm{LE}}$ to $\mathrm{TD}_{\mathrm{LE}}$.

In solutions of polar solvents, the stepwise mechanism is predicted only when the dielectric constant is sufficiently large. This prediction is consistent with the mechanism proposed by Zewail and co-workers $[29,32,45]$. When the dielectric constant of the solvent is not so large, however, ESDPT is likely to follow the concerted mechanism. In addition, when the dielectric constant is large, the potential energy profiles calculated for the stepwise ESDPT in the LE state (Path I) exhibit a much higher energy barrier for the first proton transfer than for the second proton transfer, suggesting that the first proton transfer is a rate-determining step. The second proton transfer seems to be almost barrier-less and is therefore expected to be much faster than the first proton transfer. Considering ZPE at stationary points, furthermore, the intermediate in the LE state disappears, and the concerted mechanism is more likely to be followed. Thus, for polar solvents, it is less likely to assign the faster and slower components of the biexponential decay in time-resolved electronic spectra to the first and second proton transfers, respectively, as Zewail and co-workers did [46]. Instead, similarly to the case of the gas phase and non-polar solvents, the slower component of the decay is attributed to the first proton transfer, while the faster component originates from the internal conversion from the higher excited states to the first excited state. Moreover, Zewail and co-workers revealed that the decay time of the slower component significantly depends on the solvent polarity. The present results can support this observation, because the energy of the intermediate and transition state(s) in the LE state is correlated with the solvent polarity, which should influence dynamics of the ESDPT. 


\section{Conclusions}

In the present work, we systematically investigated the effect of solvent polarity on the ESDPT in 7AI dimer to provide a comprehensive understanding of the mechanism in terms of excited-state potential-energy profiles calculated by the TDDFT/C-PCM methods. In solutions of non-polar solvents and polar solvents with the smaller dielectric constant, ESDPT in 7AI dimer is likely to take place in the LE state following the concerted mechanism. The result is well consistent with the experimental work by Takeuchi and Tahara [45]. In solutions of polar solvents with large dielectric constants, however, the adiabatic potential energy profiles for ESDPT in 7AI dimer indicates the stepwise mechanism is a preferred one. This result is consistent with the experimental work by Zewail and co-workers in polar solvents [46], but the biexponential decay in time-resolved spectra is less likely to be assigned to two proton transfer steps since the rate-determining step of ESDPT is predicted to be the first proton transfer (rather than the second proton transfer). Also, the inclusion of ZPE at stationary points along the ESDPT pathways changes the energy profiles, and suggests the possibility of the concerted mechanism again.

To the best of our knowledge, this work is the first theoretical study on the ESDPT in 7AI dimer in solutions. Together with the previous work in the gas phase [57], the present work is expected not only to provide the comprehensive analysis on the mechanism of the ESDPT behavior, but also shed a new light on the long-lasting question about the mechanism of the ESDPT in 7AI dimer in solutions. To explore this study further, dynamic simulations of the ESDPT process in solutions of non-polar and polar solvents would be an interesting topic of future studies.

\section{Acknowledgments.}

This work was supported by Grant No.ZR2015BQ013, No.ZR2016BQ06 from Shandong province in China. 


\section{References and Notes}

(1) Sobolewski, A. L.; Domcke, W.; Hättig, C. Proc. Natl. Acad. Sci. U.S.A. 2005, 102, 17903.

(2) Abo-Riziq, A.; Grace, L.; Nir, E.; Kabelac, M.; Hobza, P.; de Vries, M.S. Proc. Natl. Acad. Sci. U.S.A. 2005, 102, 20.

(3) Schwalb, N. K.; Temps, F. J. Am. Chem. Soc., 2007, 129, 9272.

(4) Groenhof, G.; Schäfer, L. V.; Boggio-Pasqua, M.; Goette, M.; Grubmüller, H.; Robb, M. A. J. Am. Chem. Soc., 2007, 129, 6812.

(5) Röttger, K.; Marroux, H. J. B.; Grubb, M. P.; Coulter, P. M.; Böhnke, H.; Henderson, A. S.; Galan, M. C.; Temps, F.; Orr-Ewing, A. J.; Roberts, G. M. Angew. Chem. Int. Ed. 2015, 54, 14719.

(6) Sobolewski, A. L.; Domcke, W. Phys. Chem. Chem. Phys. 2004, 6, 2763.

(7) Frutos, L. M.; Markmann, A.; Sobolewski, A. L.; Domcke, W. J. Phys. Chem. B 2007, 111,6110 .

(8) Chai, S.; Zhao, G-J.; Song, P.; Yang, S-Q.; Liu, J-Y.; Han, K-L. Phys. Chem. Chem. Phys., 2009, 11, 4385.

(9) Zhao, G-J.; Han, K-L. Acc. Chem. Res. 2012, 45, 404.

(10) Yamazaki, S.; Taketsugu, T. Phys. Chem. Chem. Phys. 2012, 14, 8866.

(11) Sauri, V.; Gobbo, J. P.; Serrano-Pérez, J. J.; Lundberg, M.; Coto, P. B.; Serrano-Andrés, L.; Borin, A. C.; Lindh, R.; Merchán, M.; Roca-Sanjuán, D. J. Chem. Theory Comput., 2013, 9, 481.

(12) Zhou, P-W.; Hoffmann, Mark. R.; Han, K-L.; H, G-Z. J. Phys. Chem. B. 2015, 119, 2125.

(13) Lowdin, P. O. Rev. Mod. Phys. 1963, 35, 724.

(14) Lowdin, P. O. Adv. Quantum Chem. 1965, 2, 213.

(15) Taylor, C. A.; El-Bayoumi, M. A.; Kasha, M. Proc. Natl. Acad. Sci. U.S.A. 1969, 63, 253.

(16) Ingham, K. C.; Abu-Elgheit, M.; El-Bayoumi, M. A. J. Am. Chem. Soc. 1971, 93, 5023.

(17) Ingham, K. C.; El-Bayoumi, A. M. J. Am. Chem. Soc. 1974, 96, 1674.

(18) El-Bayoumi, M. A.; Avouris, P.; Ware, W. R. J. Chem. Phys. 1975, 62, 2499.

(19) Hetherington, W. M., III; Micheels, R. H.; Eisenthal, K. E. Chem. Phys. Lett. 1979, 66, 230.

(20) Waluk, J.; Bulska, H.; Pakuła, B.; Sepioł, J. J. Lumin. 1981, 24/25, 519. 
(21) Bulska, H.; Grabowska, A.; Pakuła, B.; Sepioł, J.; Waluk, J.; Wild, U. P. J. Lumin. 1984, 29,65 .

(22) Fuke, K.; Yoshiuchi, H.; Kaya, K. J. Phys. Chem. 1984, 88, 5840.

(23) Tokumura, K.; Watanabe, Y.; Itoh, M. J. Phys. Chem. 1986, 90, 2362.

(24) Tokumura, K.; Watanabe, Y.; Udagawa, M.; Itoh, M. J. Am. Chem. Soc. 1987, 109, 1346.

(25) Fuke, K.; Kaya, K. J. Phys. Chem. 1989, 93, 614.

(26) Share, P.; Pereira, M.; Sarisky, M.; Repinec, S.; Hochstrasser, R. M. J. Lumin. 1991, 48/49, 204.

(27) Douhal, A.; Kim, S. K.; Zewail, A. H. Nature 1995, 378, 260.

(28) Takeuchi, S.; Tahara, T. Chem. Phys. Lett. 1997, 277, 340.

(29) Chachisvilis, M.; Fiebig, T.; Douhal, A.; Zewail, A. H. J. Phys. Chem. A 1998, 102, 669.

(30) Folmer, D. E.; Poth, L.; Wisniewski, E. S.; Castleman, A. W., Jr. Chem. Phys. Lett. 1998, 287,1 .

(31) Takeuchi, S.; Tahara, T. J. Phys. Chem. A 1998, 102, 7740.

(32) Fiebig, T.; Chachisvilis, M.; Manger, M.; Zewail, A. H.; Douhal, A.; Garcia-Ochoa, I.; de La Hoz Ayuso, A. J. Phys. Chem. A 1999, 103, 7419.

(33) Folmer, D. E.; Wisniewski, E. S.; Hurley, S. M.; Castleman, A. W., Jr. Proc. Natl. Acad. Sci. U.S.A. 1999, 96, 12980.

(34) Folmer, D. E.; Wisniewski, E. S.; Castleman, A. W., Jr. Chem. Phys. Lett. 2000, 318, 637.

(35) Takeuchi, S.; Tahara, T. Chem. Phys. Lett. 2001, 347, 108.

(36) Catalán, J. J. Phys. Chem. A 2002, 106, 6738.

(37) Sakota, K.; Hara, A.; Sekiya, H. Phys. Chem. Chem. Phys. 2004, 6, 32.

(38) Catalán, J.; Pérez, P.; del Valle, J. C.; de Paz, J. L. G.; Kasha, M. Proc. Natl. Acad. Sci.

U.S.A. 2004, 101, 419.

(39) Catalán, J. Phys. Chem. Chem. Phys. 2004, 6, 4467.

(40) Sakota, K.; Sekiya, H. J. Phys. Chem. A 2005, 109, 2718.

(41) Sakota, K.; Sekiya, H. J. Phys. Chem. A 2005, 109, 2722.

(42) Sakota, K.; Okabe, C.; Nishi, N.; Sekiya, H. J. Phys. Chem. A 2005, 109, 5245.

(43) Catalán, J.; de Paz, J. L. G. J. Chem. Phys. 2005, 123, 114302.

(44) Sekiya, H.; Sakota, K. Bull. Chem. Soc. Jpn. 2006, 79, 373. 
(45) Takeuchi, S.; Tahara, T. Proc. Natl. Acad. Sci. U.S.A. 2007, 104, 5285.

(46) Kwon, O.-H.; Zewail, A. H. Proc. Natl. Acad. Sci. U.S.A. 2007, 104, 8703.

(47) Sekiya, H.; Sakota, K. J. Photochem. Photobiol. C 2008, 9, 81.

(48) Catalán, J. J. Phys. Chem. A 2010, 114, 5666.

(49) Fuke, K.; Ishikawa, H. Chem. Phys. Lett. 2015, 623, 117.

(50) Pechenaya, V. I.; Danilov, V. I. Chem. Phys. Lett. 1971, 11, 539.

(51) Douhal, A.; Guallar, V.; Moreno, M.; Lluch, J. M. Chem. Phys. Lett. 1996, 256, 370.

(52) Guallar, V.; Batista, V. S.; Miller, W. H. J. Chem. Phys. 1999, 110, 9922.

(53) del Valle, J. C.; Kasha, M.; Catalán, J. Int. J. Quantum Chem. 2000, 77, 118.

(54) Moreno, M.; Douhal, A.; Lluch, J. M.; Castaño, O.; Frutos, L. M. J. Phys. Chem. A 2001, 105,3887 .

(55) Gelabert, R.; Moreno, M.; Lluch, J. M. J. Phys. Chem. A 2006, 110, 1145.

(56) Serrano-Andrés, L.; Merchán, M. Chem. Phys. Lett. 2006, 418, 569.

(57) Yu, X-f.; Yamazaki, S.; Taketsugu, T. J. Chem. Theory Comput., 2011, 7, 1006.

(58) Yu, X-f.; Yamazaki, S.; Taketsugu, T. J. Comp. Chem., 2012, 33, 1701.

(59) Ando, K.; Hayashi, S.; Kato, S. Phys. Chem. Chem. Phys., 2011, 13, 11118.

(60) Crespo-Otero, R.; Kungwan, N.; Barbatti, M. Chem. Sci. 2015, 6, 5762.

(61) Yanai, T.; Tew, D.; Handy, N. Chem. Phys. Lett., 2004, 393, 51-57.

(62) Schmidt, M.W.; Baldridge, K. K.; Boatz, J. A.; Elbert, S. T.; Gordon, M. S.; Jensen, J.

H.; Koseki, S.; Matsunaga, N.; Nguyen, K. A.; Su, S.; Windus, T. L.; Dupuis, M.; Montgomery, J. A., Jr. J. Comput. Chem. 1993, 14, 1347.

(63) Cossi, M.; Rega, N.; Scalmani, G.; Barone, V. J. Comp. Chem. 2003, 24, 669.

(64) Barone, V.; Cossi, M. J. Phys. Chem. A 1998, 102, 1995.

(65) Shirota, H.; Fukuda, T.; Kato, T. J. Phys. Chem. B. 2013, 117, 16196. 
Table 1. TD-CAM-B3LYP electronic energies of minimum and transition state structures, relative to $\mathrm{ND}_{\mathrm{LE}}$ (in $\mathrm{kcal} / \mathrm{mol}$ ). The value in the parentheses is the dipole moment (in Debye). The value in italic is the energy including zero-point vibrational energy.

\begin{tabular}{|c|c|c|c|c|c|c|c|c|c|c|}
\hline solvent & gas phase & heptane & cyclohexane & benzene & $\begin{array}{l}\text { diethyl } \\
\text { ether }\end{array}$ & chloroform & $\begin{array}{c}\text { dichlorom } \\
\text { ethane }\end{array}$ & methanol & acetonitrile & water \\
\hline $\begin{array}{l}\text { static } \\
\text { dielectric } \\
\text { constant }\end{array}$ & & 1.92 & 2.02 & 2.25 & 4.34 & 4.90 & 8.93 & 32.63 & 36.64 & 78.39 \\
\hline $\mathrm{ND}_{\mathrm{LE}}$ & $\begin{array}{c}0.00 \\
(3.83)\end{array}$ & $\begin{array}{c}0.00 \\
(4.38)\end{array}$ & $\begin{array}{c}0.00 \\
(4.41)\end{array}$ & $\begin{array}{c}0.00 \\
(4.48)\end{array}$ & $\begin{array}{c}0.00 \\
(4.81)\end{array}$ & $\begin{array}{c}0.00 \\
(4.83)\end{array}$ & $\begin{array}{c}0.00 \\
(4.99)\end{array}$ & $\begin{array}{c}0.00 \\
(5.12)\end{array}$ & $\begin{array}{c}0.00 \\
(5.13)\end{array}$ & $\begin{array}{c}0.00 \\
(5.14)\end{array}$ \\
\hline $\mathrm{TD}_{\mathrm{LE}}$ & $\begin{array}{l}-8.16 \\
(3.35) \\
-7.21\end{array}$ & $\begin{array}{c}-7.03 \\
(4.08) \\
-6.10\end{array}$ & $\begin{array}{l}-6.96 \\
(4.14) \\
-6.01\end{array}$ & $\begin{array}{l}-6.83 \\
(4.22) \\
-5.89\end{array}$ & $\begin{array}{l}-6.24 \\
(4.71) \\
-5.24\end{array}$ & $\begin{array}{l}-6.16 \\
(4.77) \\
-5.36\end{array}$ & $\begin{array}{l}-5.83 \\
(5.01) \\
-5.00\end{array}$ & $\begin{array}{l}-5.38 \\
(5.18) \\
-4.52\end{array}$ & $\begin{array}{l}-5.53 \\
(5.24) \\
-4.42\end{array}$ & $\begin{array}{c}-5.46 \\
(5.28) \\
-4.37\end{array}$ \\
\hline $\mathrm{INT}_{\mathrm{CT}}$ & $\begin{array}{c}-28.81 \\
(10.29) \\
-28.53^{\mathrm{a}}\end{array}$ & $\begin{array}{c}-15.18 \\
(12.15) \\
-14.58\end{array}$ & $\begin{array}{c}-14.41 \\
(12.24) \\
-13.79\end{array}$ & $\begin{array}{c}-13.01 \\
(12.38) \\
-12.36\end{array}$ & $\begin{array}{c}-6.81 \\
(13.13) \\
-5.78\end{array}$ & $\begin{array}{c}-6.01 \\
(13.23) \\
-5.17\end{array}$ & $\begin{array}{c}-3.17 \\
(13.59) \\
-2.19\end{array}$ & $\begin{array}{c}-0.63 \\
(13.90) \\
0.27\end{array}$ & $\begin{array}{c}-0.52 \\
(13.92) \\
1.06\end{array}$ & $\begin{array}{c}-0.06 \\
(13.98) \\
0.96\end{array}$ \\
\hline $\mathrm{INT}_{\mathrm{LE}}$ & & & & & & & $\begin{array}{c}4.19 \\
(10.27) \\
3.27\end{array}$ & $\begin{array}{c}4.02 \\
(10.72) \\
3.58\end{array}$ & $\begin{array}{c}4.02 \\
(10.86) \\
3.23\end{array}$ & $\begin{array}{c}3.98 \\
(10.92) \\
3.40\end{array}$ \\
\hline $\mathrm{TS}_{\mathrm{LE}}$ & $\begin{array}{c}6.13 \\
(5.94) \\
2.39\end{array}$ & $\begin{array}{c}6.06 \\
(7.12) \\
2.73\end{array}$ & $\begin{array}{c}6.04 \\
(7.18) \\
2.74\end{array}$ & $\begin{array}{c}6.04 \\
(7.30) \\
2.76\end{array}$ & $\begin{array}{c}5.97 \\
(7.81) \\
2.76\end{array}$ & $\begin{array}{c}5.95 \\
(7.88) \\
2.59\end{array}$ & & & & \\
\hline $\mathrm{TS}_{\mathrm{LE} 1}$ & & & & & & & $\begin{array}{c}5.92 \\
(8.11) \\
2.85\end{array}$ & $\begin{array}{c}5.94 \\
(8.34) \\
3.14\end{array}$ & $\begin{array}{c}5.89 \\
(8.33) \\
2.85\end{array}$ & $\begin{array}{c}5.88 \\
(8.37) \\
2.88\end{array}$ \\
\hline $\mathrm{TS}_{\mathrm{LE} 2}$ & & & & & & & $\begin{array}{c}4.25 \\
(9.35) \\
2.29\end{array}$ & $\begin{array}{c}4.20 \\
(9.38) \\
2.04\end{array}$ & $\begin{array}{c}4.20 \\
(9.39) \\
2.02\end{array}$ & $\begin{array}{c}4.19 \\
(9.42) \\
2.03\end{array}$ \\
\hline
\end{tabular}




\begin{tabular}{cccccccccccc} 
TS $_{\text {Mix }}$ & 6.74 & 7.00 & 7.00 & 7.03 & 7.14 & 7.14 & 7.19 & 7.23 & 7.24 & 7.24 \\
& $(4.64)$ & $(5.86)$ & $(5.92)$ & $(6.06)$ & $(6.61)$ & $(6.68)$ & $(6.93)$ & $(7.16)$ & $(7.17)$ & $(7.21)$ \\
& 2.51 & 3.42 & 3.46 & 3.56 & 3.91 & 3.77 & 4.18 & 4.35 & 4.34 & 4.38 \\
\hline
\end{tabular}

${ }^{\mathrm{a}}$ with an imaginary frequency of $7.52 \mathrm{i} \mathrm{cm}^{-1}$. 
Table 2. Excitation energies at $\mathrm{ND}_{\mathrm{S} 0}$ and emission energies at $\mathrm{ND}_{\mathrm{LE}}, \mathrm{TD}_{\mathrm{LE}}, \mathrm{INT}_{\mathrm{CT}}$ and $\mathrm{INT}_{\mathrm{LE}}$ of $7 \mathrm{AI}$ dimer in solutions calculated at the TD-CAM-B3LYP and TD-B3LYP levels (in eV). The value in the parentheses is the oscillator strength at each level, and the value in italic is the energy calculated at the TD-B3LYP level.

\begin{tabular}{|c|c|c|c|c|c|c|c|c|c|c|c|}
\hline solvent & gas phase & heptane & cyclohexane & benzene & $\begin{array}{c}\text { diethyl } \\
\text { ether }\end{array}$ & chloroform & $\begin{array}{l}\text { dichloro } \\
\text { methane }\end{array}$ & methanol & acetonitrile & water & exp. \\
\hline \multirow[t]{4}{*}{$\mathrm{ND}_{\mathrm{S} 0}$} & 4.85 & 4.84 & 4.83 & 4.83 & 4.85 & 4.84 & 4.85 & 4.85 & 4.85 & 4.86 & \multirow{4}{*}{$\begin{array}{l}4.32^{\mathrm{a}}, \\
4.34^{\mathrm{b}}\end{array}$} \\
\hline & $(0.136)$ & $(0.196)$ & $(0.201)$ & $(0.210)$ & $(0.193)$ & $(0.205)$ & $(0.203)$ & $(0.190)$ & $(0.192)$ & $(0.191)$ & \\
\hline & 4.46 & 4.45 & 4.45 & 4.45 & 4.46 & 4.45 & 4.45 & 4.46 & 4.46 & 4.46 & \\
\hline & $(0.105)$ & $(0.146)$ & $(0.149)$ & $(0.155)$ & $(0.144)$ & $(0.152)$ & $(0.150)$ & $(0.142)$ & $(0.144)$ & $(0.143)$ & \\
\hline \multirow[t]{4}{*}{$\mathrm{ND}_{\mathrm{LE}}$} & 3.96 & 3.94 & 3.94 & 3.94 & 3.93 & 3.92 & 3.91 & 3.90 & 3.90 & 3.90 & \multirow[t]{4}{*}{$3.54^{\mathrm{c}}$} \\
\hline & \multirow[t]{3}{*}{$(0.086)$} & $(0.127)$ & $(0.130)$ & $(0.136)$ & $(0.168)$ & $(0.171)$ & $(0.191)$ & (0.209) & $(0.210)$ & $(0.210)$ & \\
\hline & & 3.60 & 3.60 & 3.60 & 3.63 & 3.63 & 3.64 & 3.65 & 3.65 & 3.66 & \\
\hline & & $(0.086)$ & $(0.089)$ & (0.093) & (0.091) & (0.097) & (0.098) & $(0.096)$ & (0.097) & (0.097) & \\
\hline \multirow[t]{4}{*}{$\mathrm{TD}_{\mathrm{LE}}$} & 2.80 & 2.87 & 2.88 & 2.88 & 2.91 & 2.92 & 2.93 & 2.95 & 2.94 & 2.95 & \multirow[t]{6}{*}{$2.53^{d}$} \\
\hline & $(0.024)$ & $(0.035)$ & $(0.036)$ & $(0.038)$ & $(0.047)$ & $(0.048)$ & $(0.053)$ & $(0.059)$ & $(0.058)$ & $(0.059)$ & \\
\hline & & 2.59 & 2.59 & 2.60 & 2.64 & 2.65 & 2.64 & 2.69 & 2.69 & 2.69 & \\
\hline & & $(0.0260$ & $(0.027)$ & $(0.028)$ & $(0.028)$ & $(0.03)$ & $(0.028)$ & (0.03) & $(0.03)$ & $(0.03)$ & \\
\hline \multirow[t]{2}{*}{$\mathrm{INT}_{\mathrm{CT}}$} & 1.01 & 2.14 & 2.19 & 2.27 & 2.69 & 2.74 & 2.93 & 3.09 & 3.10 & 3.12 & \\
\hline & $(0.002)$ & $(0.002)$ & $(0.002)$ & $(0.002)$ & $(0.003)$ & $(0.003)$ & $(0.004)$ & $(0.005)$ & $(0.005)$ & $(0.005)$ & \\
\hline
\end{tabular}




$\begin{array}{lllllllll}0.718 & 0.766 & 0.842 & 1.26 & 1.31 & 1.50 & 1.65 & 1.66 & 2.44 \\ (0.005) & (0.005) & (0.004) & (0.004) & (0.004) & (0.004) & (0.004) & (0.004) & (0.005)\end{array}$

$\mathrm{INT}_{\mathrm{LE}}$

$\begin{array}{cccc}3.38 & 3.39 & 3.40 & 3.40 \\ (0.095) & (0.103) & (0.106) & (0.107) \\ 2.37 & 2.44 & 2.42 & 2.56 \\ (0.005) & (0.005) & (0.005) & (0.0)\end{array}$

a Absorption band maximum in hexane [45].

b Absorption band maximum in 3-methylpentane and ethylcyclohexane [48].

c Fluorescence band maximum in 3-methylpentane and ethylcyclohexane [48].

$\mathrm{d}$ Fluorescence band maximum in hexane [45]. 
Table 3. 7AI dimerization energies in the gas phase and in solutions, and solvation energies of 7AI monomer and dimer (NDs0) calculated with nine solvents at the CAM-B3LYP level (in $\mathrm{kcal} / \mathrm{mol}$ ). The values in parentheses are solvation energies for 7AI monomer.

\begin{tabular}{|c|c|c|c|c|c|c|c|c|c|c|}
\hline & \multirow{2}{*}{ gas phase } & \multicolumn{9}{|c|}{ in solutions } \\
\hline & & heptane & cyclohexane & benzene & $\begin{array}{l}\text { diethyl } \\
\text { ether }\end{array}$ & chloroform & $\begin{array}{c}\text { dichlorom } \\
\text { ethane }\end{array}$ & methanol & acetonitrile & water \\
\hline $\begin{array}{l}\text { Dimerization } \\
\text { energy }\end{array}$ & $\begin{array}{l}-19.18 \\
\end{array}$ & -16.33 & -16.17 & -15.85 & -14.45 & -14.27 & -13.65 & -13.08 & -13.05 & -12.95 \\
\hline $\begin{array}{l}\text { Solvation } \\
\text { energy }\end{array}$ & & $\begin{array}{c}-2.04 \\
(-2.48)\end{array}$ & $\begin{array}{c}-2.16 \\
(-2.63)\end{array}$ & $\begin{array}{l}-2.39 \\
(-2.90)\end{array}$ & $\begin{array}{l}-3.41 \\
(-4.13)\end{array}$ & $\begin{array}{c}-3.54 \\
(-4.29)\end{array}$ & $\begin{array}{c}-3.99 \\
(-4.84)\end{array}$ & $\begin{array}{c}-4.41 \\
(-5.34)\end{array}$ & $\begin{array}{c}-4.43 \\
(-5.36)\end{array}$ & $\begin{array}{l}-5.00 \\
(-5.45)\end{array}$ \\
\hline
\end{tabular}




\section{Figure Captions}

Figure 1. Molecular structure of 7AI dimer and a definition of reaction coordinates for ESDPT. Labels for atoms are also given.

Figure 2. Equilibrium geometries of 7AI dimer in the $\mathrm{S}_{1}$ state, optimized at the TD-CAM-B3LYP/PCM level: (a) ND $D_{L E}$, (b) TD $D_{L E}$ and (c) INT $_{\mathrm{CT}}$ in heptane, and (d) INT $\mathrm{LE}$ in acetonitrile. Bond lengths are in angstroms. The monomer in [ ]* indicates Monomer-e.

Figure 3. Frontier orbitals mainly involved in the $\mathrm{S}_{1}$ excitation at (a) $\mathrm{ND}_{\mathrm{LE}}$, (b) $\mathrm{TD}_{\mathrm{LE}}$, and (c) $\mathrm{INT}_{\mathrm{CT}}$ in heptane and (d) $\mathrm{INT}_{\mathrm{LE}}$ in acetonitrile.

Figure 4. Transition state structures optimized in the LE state at the TD-CAM-B3LYP/PCM level: (a) TS $S_{L E}$ in heptane, and (b) TS $\mathrm{LE}_{\text {, }}$ (c) $\mathrm{TS}_{\mathrm{LE} 2}$ and (d) $\mathrm{TS}_{\mathrm{Mix}}$ in acetonitrile. Bond lengths are in angstroms. The monomer in [ ]* indicates Monomer-e.

Figure 5. Potential energy curves along cMEPs in LE state as a function of the reaction coordinate $Q$ in solutions of non-polar solvents, heptane, cyclohexane and benzene. Filled marks indicate true minima $\left(\mathrm{ND}_{\mathrm{LE}}\right.$ and $\left.\mathrm{TD}_{\mathrm{LE}}\right)$ and transition state $\left(\mathrm{TS}_{\mathrm{LE}}\right)$.

Figure 6. Potential energy curves of the ground state and the lowest 6 excited states along cMEPs as a function of the reaction coordinate $Q$ in a solution of non-polar solvent, heptane.

Figure 7. Potential energy curves along cMEPs in LE state as a function of the reaction coordinate $Q$ in solutions of polar solvents, (a) diethyl ether, and chloroform, and (b) dichloromethane, methanol, acetonitrile, and water. Filled marks indicate true minima $\left(\mathrm{ND}_{\mathrm{LE}}\right.$, INT $_{\mathrm{LE}}$ and $\left.\mathrm{TD}_{\mathrm{LE}}\right)$ and transition states $\left(\mathrm{TS}_{\mathrm{LE} 1}\right.$ and $\left.\mathrm{TS}_{\mathrm{LE} 2}\right)$.

Figure 8. Potential energy curves along (a) IRC paths (coordinate $s$ ) from $\mathrm{ND}_{\mathrm{LE}}$ to $\mathrm{TD}_{\mathrm{LE}}$ in benzene, diethyl ether, chloroform, dichloromethane, methanol, acetonitrile, and water, and (b) IRC paths from $\mathrm{ND}_{\mathrm{LE}}$ to INT $\mathrm{CT}_{\mathrm{CT}}$ in heptane and cyclohexane. 
Figure 9. Potential energy curves along cMEPs for the first proton transfer (left) and second proton transfer (right) processes involving $\mathrm{CT}$ state as a function of the reaction coordinates $M_{1}$ and $M_{2}$, respectively, in solutions of non-polar solvents heptane, cyclohexane and benzene. Filled marks indicate true minima ( $\mathrm{ND}_{\mathrm{LE}}, \mathrm{INT}_{\mathrm{CT}}$ and $\left.\mathrm{TD}_{\mathrm{LE}}\right)$.

Figure 10. Potential energy curves along cMEPs for the first proton transfer (left) and second proton transfer (right) processes involving CT state as a function of the reaction coordinates $M_{1}$ and $M_{2}$, respectively, in solutions of polar solvents, diethyl ether, chloroform, dichloromethane, methanol, acetonitrile and water. Filled marks indicate true minima $\left(\mathrm{ND}_{\mathrm{LE}}, \mathrm{INT}_{\mathrm{CT}}\right.$ and $\left.\mathrm{TD}_{\mathrm{LE}}\right)$. 
Figure 1

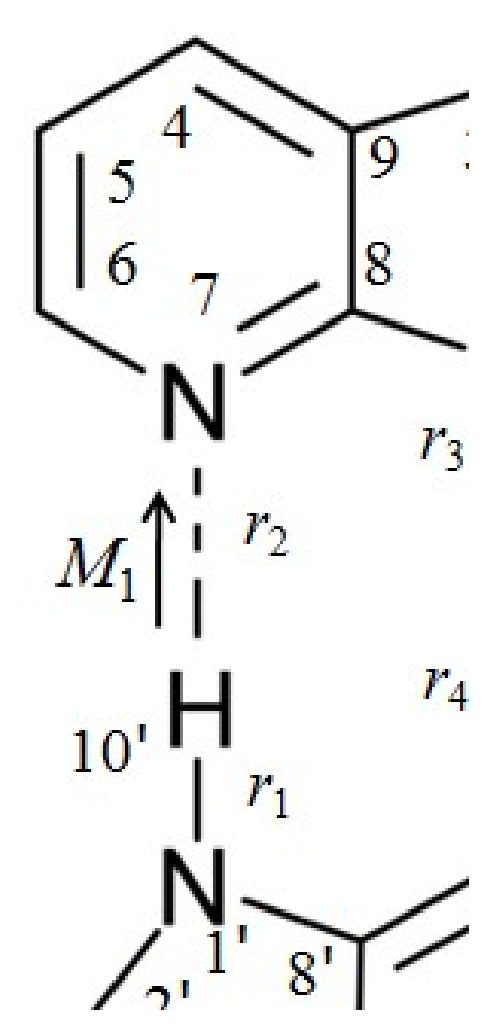


Figure 2

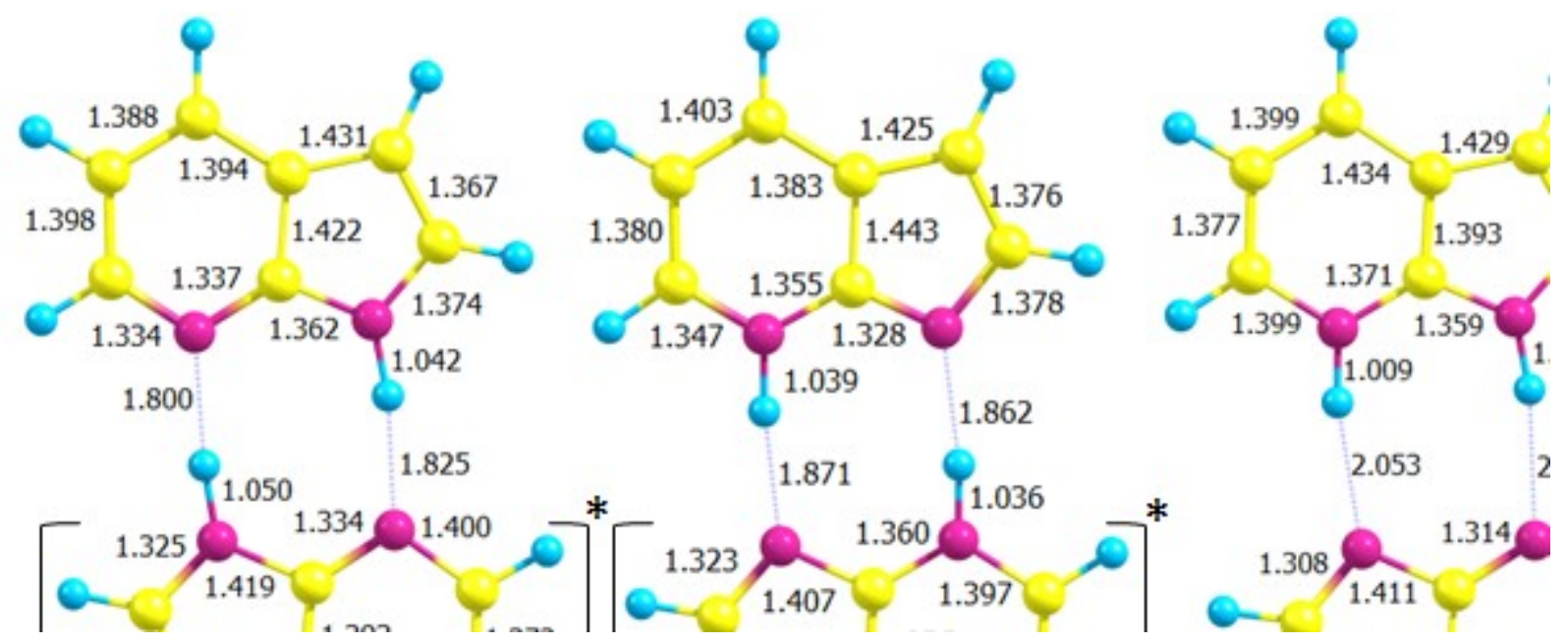


Figure 3
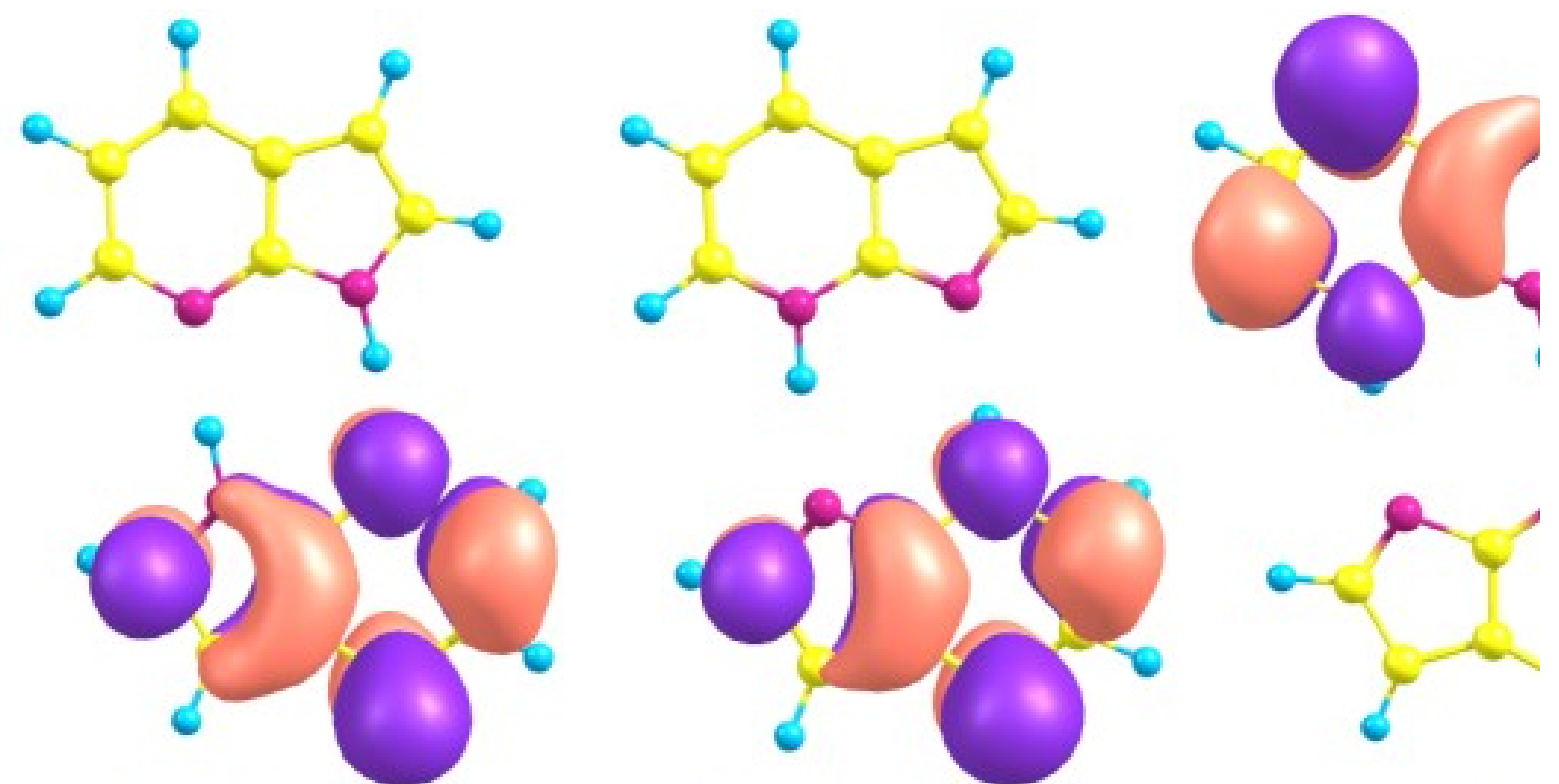

LUMO of $\mathrm{ND}_{\mathrm{LE}}$

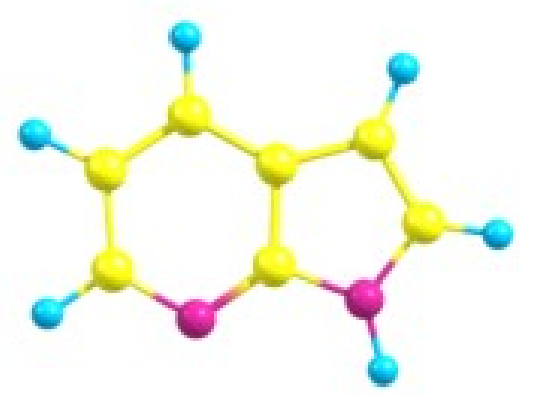

LUMO of $\mathrm{TD}_{\mathrm{LE}}$

LUMO of IN
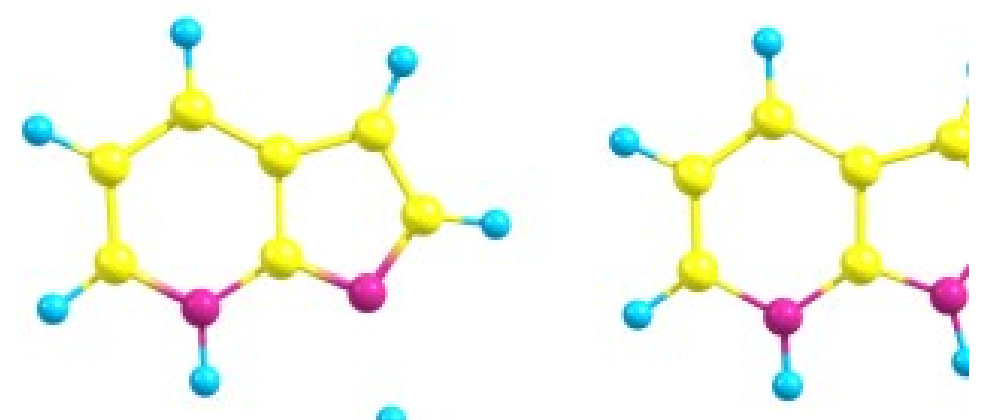
Figure 4

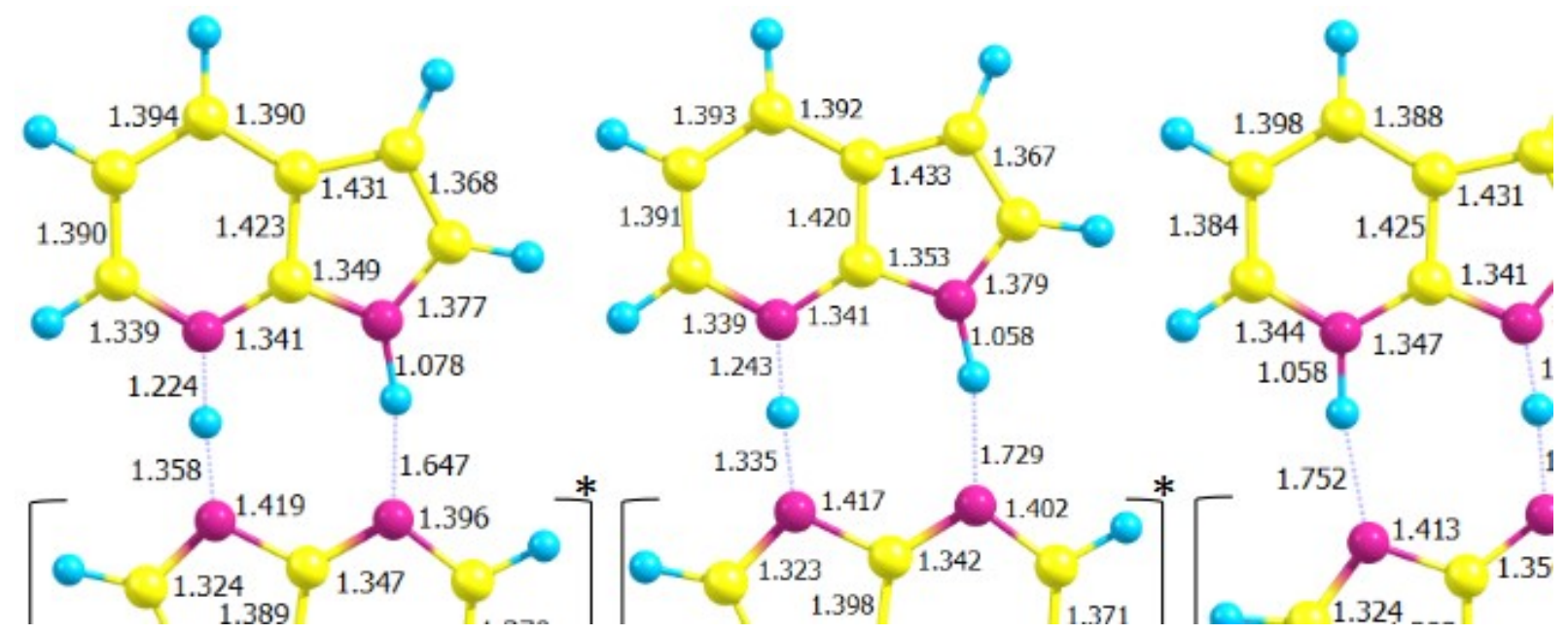


Figure 5

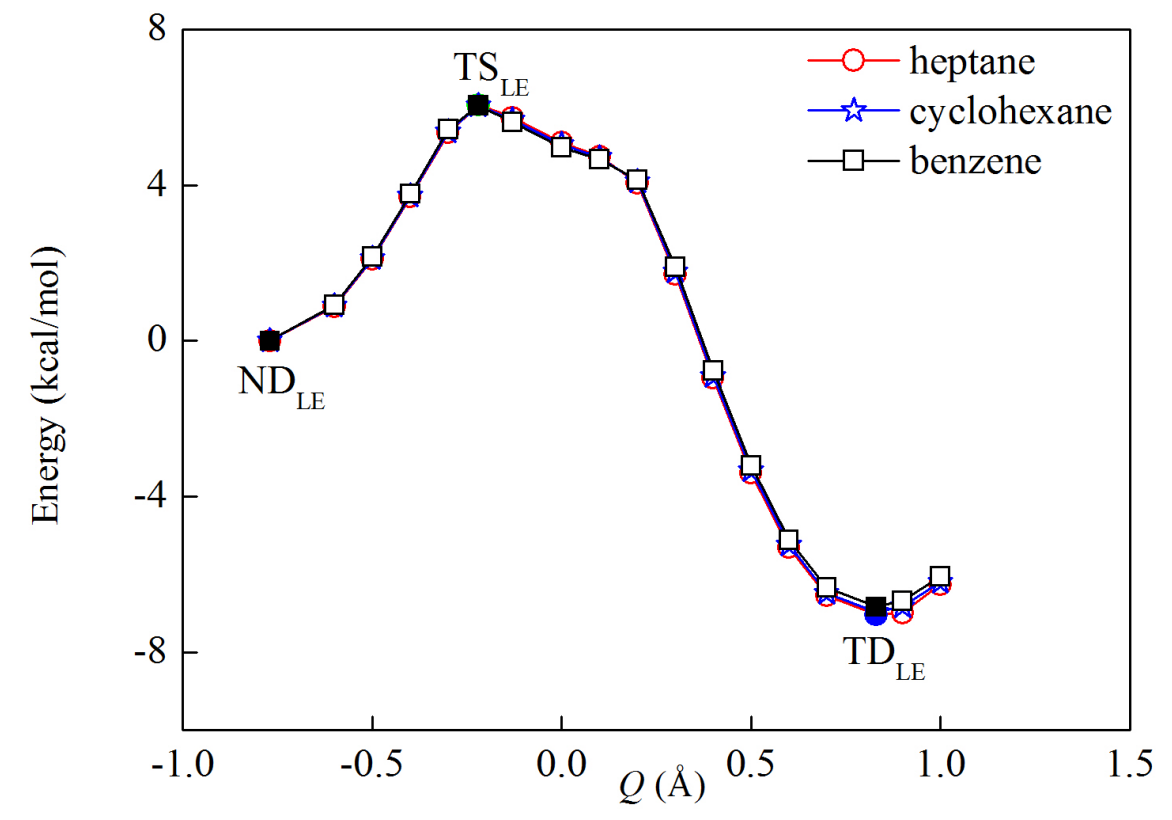


Figure 6

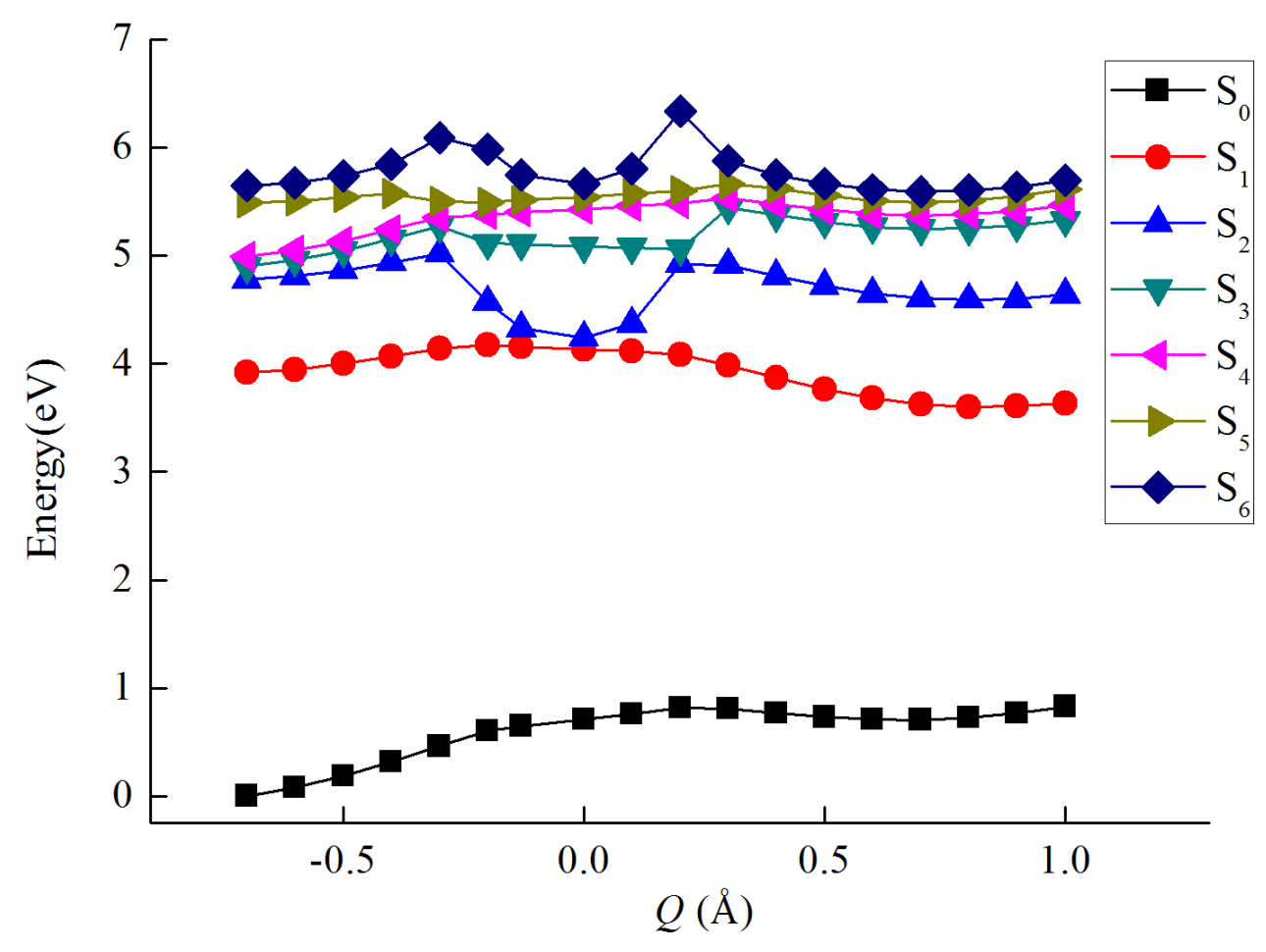


Figure 7 


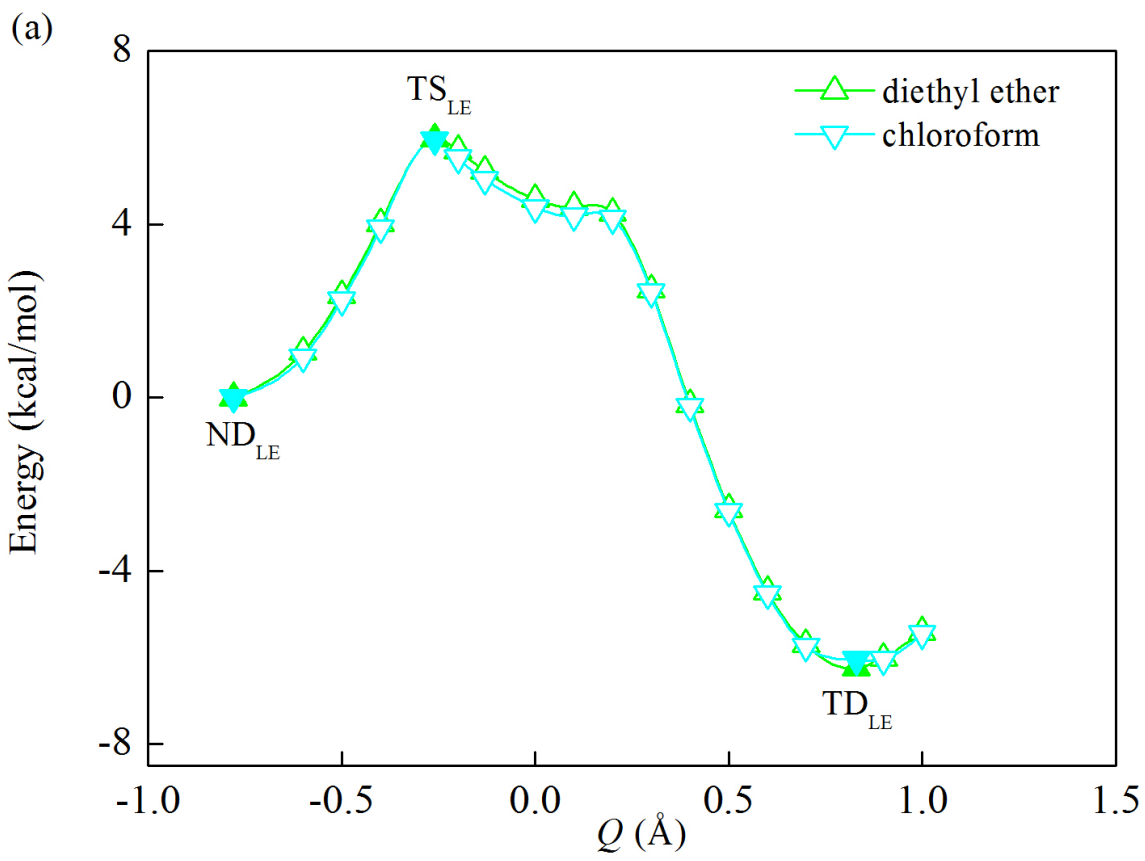




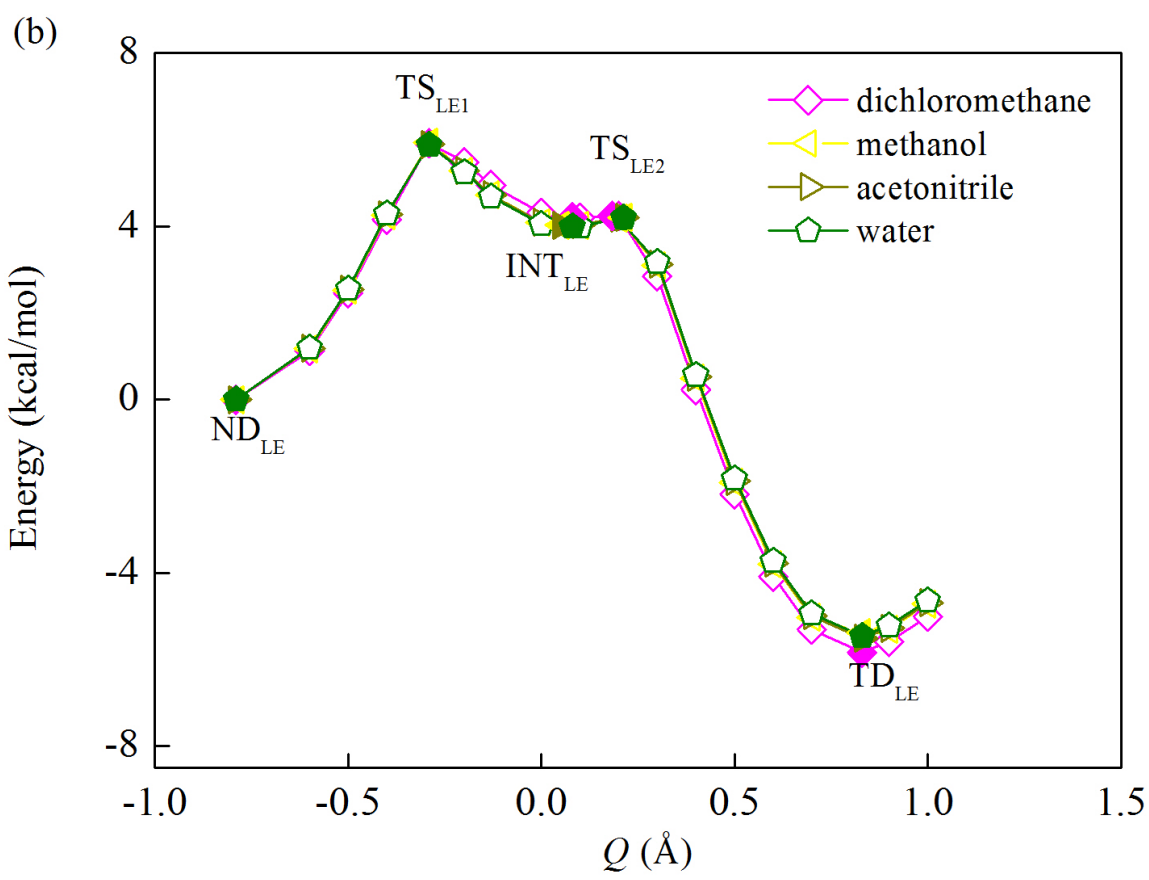


Figure 8 


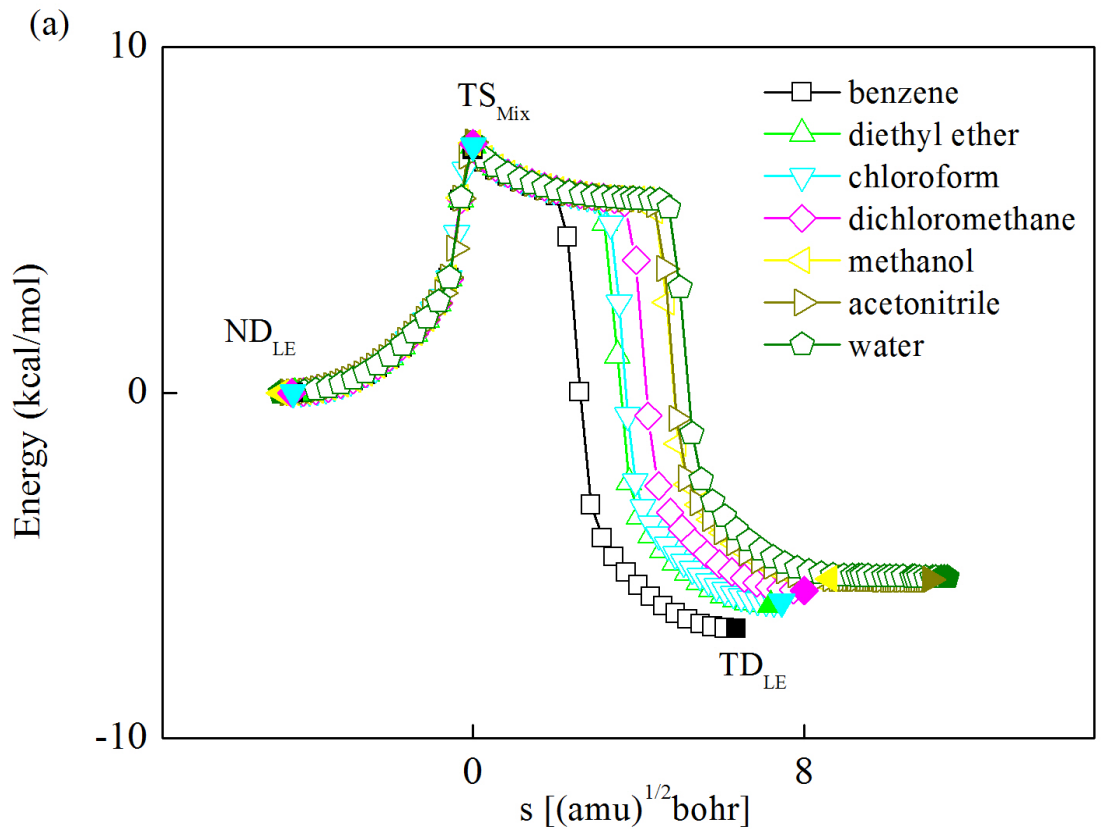




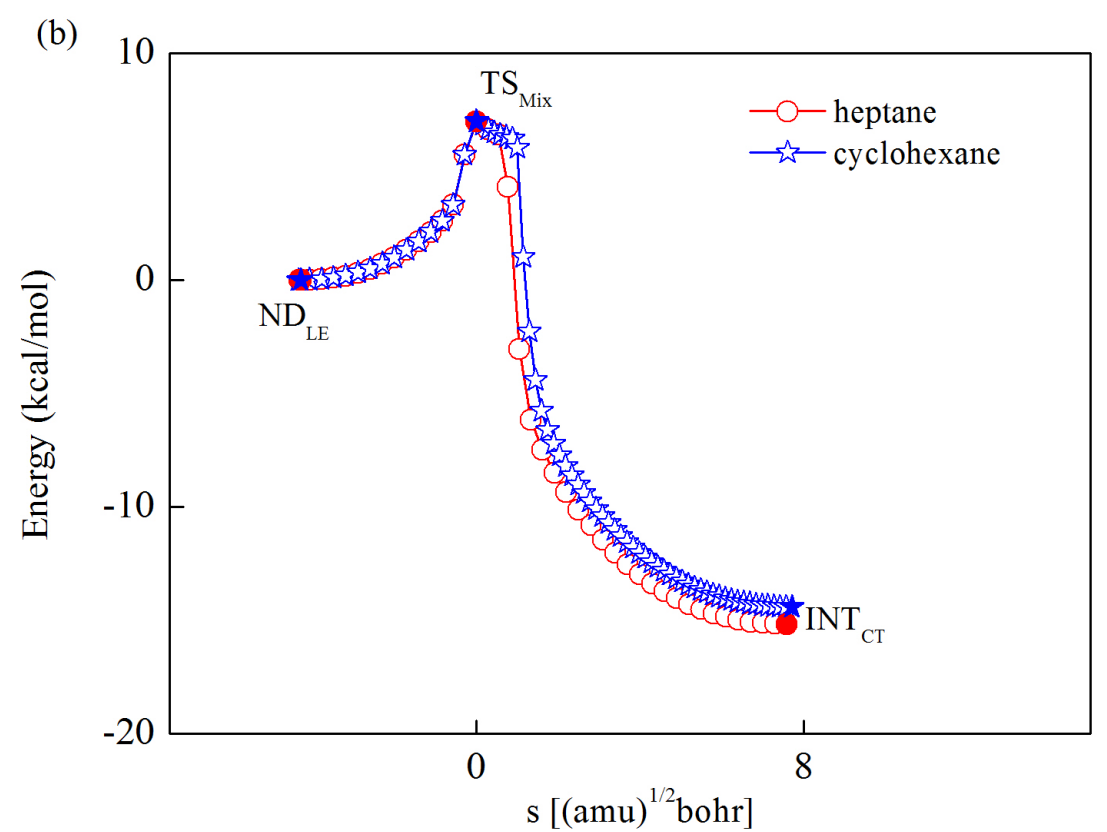


Figure 9

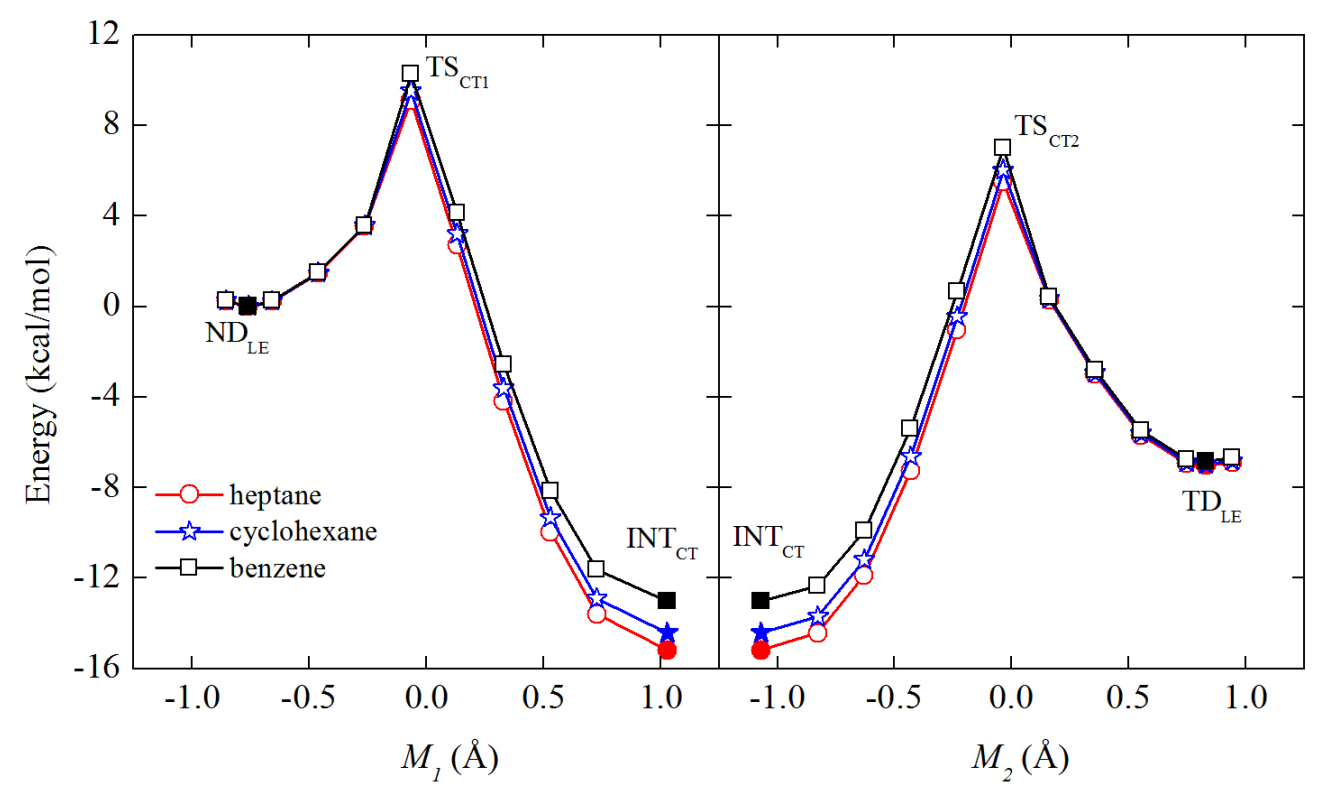


Figure 10

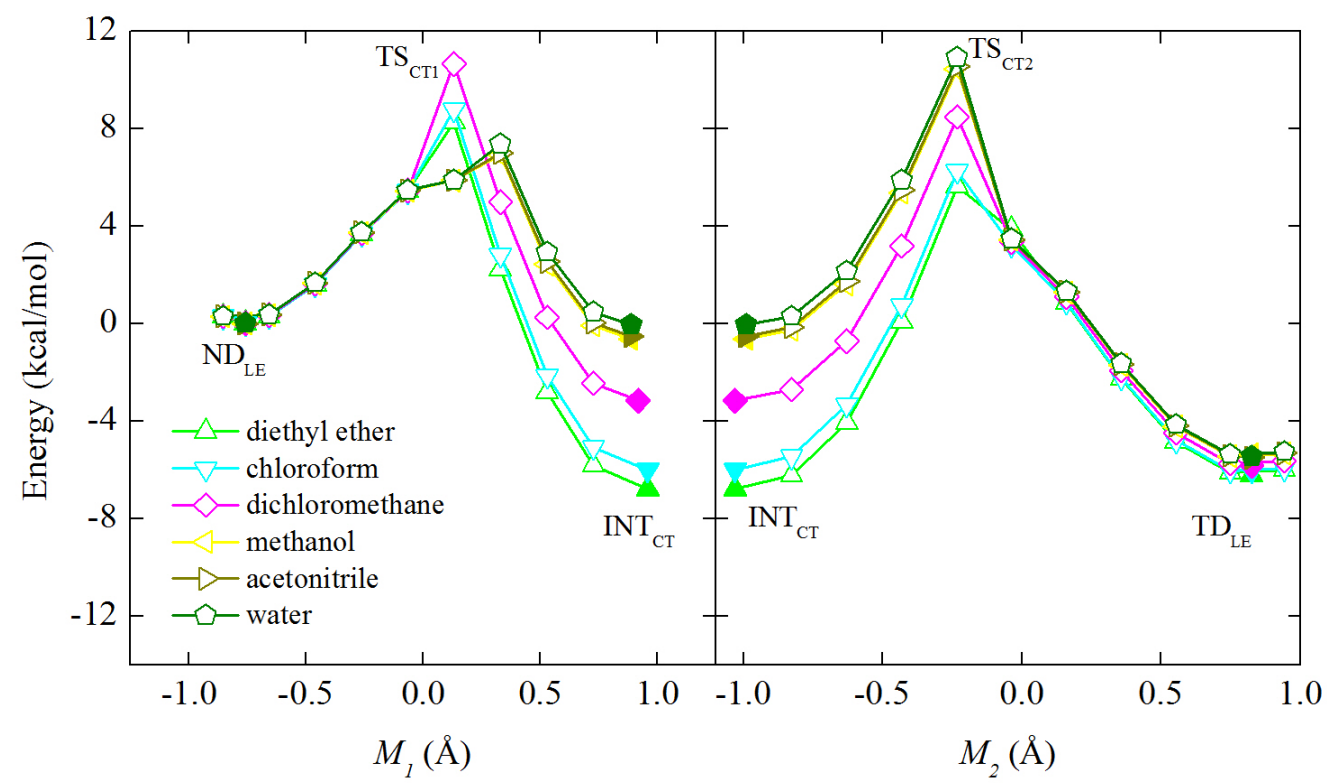

